\title{
Enhancement of aerosol characterization using synergy of lidar and sun-photometer coincident observations: the GARRLiC algorithm
}

\author{
A. Lopatin ${ }^{1,2}$, O. Dubovik ${ }^{2}$, A. Chaikovsky ${ }^{1}$, P. Goloub ${ }^{2}$, T. Lapyonok ${ }^{2}$, D. Tanré2 ${ }^{2}$ and P. Litvinov ${ }^{2}$ \\ ${ }^{1}$ Laboratory of scattering media, NASB - B. I. Stepanov Institute of Physics, Minsk, Belarus \\ ${ }^{2}$ Laboratoire d'Optique Atmosphérique, CNRS - UMR8518, Université de Lille 1, Villeneuve d'Ascq, France
}

Correspondence to: A. Lopatin (anton.lapatsin@ed.univ-lille1.fr, lopatsin@scat.bas-net.by)

Received: 29 January 2013 - Published in Atmos. Meas. Tech. Discuss.: 1 March 2013

Revised: 5 June 2013 - Accepted: 10 July 2013 - Published: 20 August 2013

\begin{abstract}
This paper presents the GARRLiC algorithm (Generalized Aerosol Retrieval from Radiometer and Lidar Combined data) that simultaneously inverts coincident lidar and radiometer observations and derives a united set of aerosol parameters. Such synergetic retrieval results in additional enhancements in derived aerosol properties because the back-scattering observations by lidar improve sensitivity to the columnar properties of aerosol, while radiometric observations provide sufficient constraints on aerosol amount and type that are generally missing in lidar signals.

GARRLiC is based on the AERONET algorithm, improved to invert combined observations by radiometer and multi-wavelength elastic lidar observations. The algorithm is set to derive not only the vertical profile of total aerosol concentration but it also differentiates between the contributions of fine and coarse modes of aerosol. The detailed microphysical properties are assumed height independent and different for each mode and derived as a part of the retrieval. The GARRLiC inversion retrieves vertical distribution of both fine and coarse aerosol concentrations as well as the size distribution and complex refractive index for each mode.

The potential and limitations of the method are demonstrated by the series of sensitivity tests. The effects of presence of lidar data and random noise on aerosol retrievals are studied. Limited sensitivity to the properties of the fine mode as well as dependence of retrieval accuracy on the aerosol optical thickness were found. The practical outcome of the approach is illustrated by applications of the algorithm to the real lidar and radiometer observations obtained over Minsk AERONET site.
\end{abstract}

\section{Introduction}

Atmospheric aerosols are known to be important part of the complex physical-chemical processes that impact Earth's climate. Such impacts take their effects both on global and regional scales (e.g. D'Almeida et al., 1991; Charlson et al., 1992; Hobbs, 1993; Pilinis et al., 1995; Ramanathan et al., 2001; Forster et al., 2007; Hansen et al., 2011). Also, aerosol pollution affects a population's health (e.g. Jones, 1999; Harrison and Yin, 2000) and ecological equilibrium (e.g. Barker and Tingey, 1992).

In order to estimate these impacts, a large variety of methods for monitoring atmospheric aerosols were developed. Among others, remote sensing methods, both active and passive, proved to be fruitful and convenient. A number of developed and launched space instruments (e.g. Bréon et al., 2002; Winker et al., 2007) provide global monitoring of aerosol properties (e.g. King et al., 1999; Kokhanovsky et al., 2007). Observations by ground-based instruments generally provide more detailed and accurate information about aerosol properties (e.g. Nakajima et al., 1996; Dubovik and King, 2000) but cover only the local area near the observation site. In order to obtain such data at extended geographical scales, the ground-based observations are often collected within observational networks employing identical instrumentation and standardized data processing procedures. At present, there is a number of global and regional networks conducting both passive and active ground-based observations. For example, the global AERONET (Holben, 1998) and East Asian SKYNET (Nakajima et al., 2007) networks of sun photometers, as well as, a variety of lidar networks including regional EARLINET (Bösenberg, 2000), ADNET (Murayama et al., 
2001), MPL-Net (Welton et al., 2002), ALiNe (Antuña et al., 2006), Cis-LiNet (Chaikovsky et al., 2006b) and a recent global lidar network GALION (Bösenberg and Hoff, 2007) have been established during the last two decades. Aerosol data collected by these networks provide valuable aerosol information that is widely used for validating satellite observations (e.g. Remer et al., 2002, 2005; Schuster et al., 2012; Hasekamp et al., 2011; Yoon et al., 2011; Kahn et al., 2010; Ahmad et al., 2010) and constraining aerosol properties in climate simulation efforts (e.g. Kinne et al., 2003, 2006; Textor et al., 2006; Koch et al., 2009).

Despite of the achieved progress in aerosol remote sensing the limited accuracy in the knowledge of aerosol properties remains one of the main uncertainties in climate assessments (Forster et al., 2007; Hansen et al., 2011). The expected improvements in the ground-based aerosol monitoring are associated with two kinds of efforts: (i) enhancement of the observation completeness by employing a variety of complimentary observational techniques and (ii) improvement of the accuracy of derived aerosol information. For example, the number of extensive multi-instrumental aerosol campaigns have been organized (e.g. Russell et al., 1999; Raes et al., 2000; Ramanathan et al., 2001; Müller et al., 2003; Papayannis et al., 2005; McKendry et al., 2007; Huebert et al., 2003; Ansmann et al., 2011a; Holben et al., 2011). In addition, the number of permanent monitoring sites equipped with several instruments is continuously increasing (e.g. Takamura et al., 1994; Waquet et al., 2005; Müller et al., 2004; Ansmann et al., 2010). In these regards, the columnar properties of aerosol derived by the photometers and aerosol vertical profiles provided by the lidars are clearly complimentary pieces of information about aerosol, both important for climatic studies. Specifically, the columnar properties are important for direct aerosol forcing estimations both on global and regional scales (Pilinis et al., 1995; Costa et al., 2004). On the other hand, the vertical structure of the aerosol is needed for accounting of the indirect effects like influence on cloud formation (McCormick et al., 1993; Bréon, 2006). The importance of obtaining simultaneous information about both columnar and vertical aerosol properties is rather evident for the scientific community, and, a substantial number of sites within ground-based networks conducting coincident lidar and photometric measurements have been established.

In addition, the accumulation of a variety of complementary data is not the only positive effect. It also helps to improve the accuracy of the obtained data and derive qualitatively new aerosol characteristics. Indeed, processing of both passive and active remote measurements relies on a set of several assumptions. For example, retrievals of aerosol columnar properties from passive methods use an assumption of the vertical distribution of aerosol. The uncertainties in this assumption may have a notable effect on the retrieval result, especially in the case of polarimetric observations. Retrievals from active sounding, on the other hand, deal with relatively limited information from the altitude profiles of the spectral backscattering and usually rely on assumptions about aerosol columnar properties. For example, information about aerosol type is usually used for constraining the lidar ratio that defines relation between aerosol backscatter and extinction. Combined with known boundary conditions, this provides missing information and allows quantitative interpretation of lidar signals and retrieval of vertical profiles of aerosol backscatter and extinction (Klett, 1981, 1985). Commonly, the lidar ratio is chosen using a priori climatological data sets. For example, processing of lidar observations from the CALIPSO spaceborne platform relies on the climatological models of lidar ratio derived by cluster analysis of the entire database of AERONET retrievals obtained for $\sim 10 \mathrm{yr}$ of observations (Omar et al., 2005). However, inconsistencies in the chosen lidar ratio directly propagate into derived results and may strongly affect the lidar retrievals (Sasano et al., 1985; Kovalev, 1995). The most reliable and therefore preferable approach is to define lidar ratio using coincident measurement by developing enhanced lidar capabilities or by obtaining missing information from other instruments (Ferrare et al., 1998a; Gobbi et al., 2003). For example, enhancement of lidar observation can be achieved by employing lidar systems registering combined elastic-Raman signals (Ansmann et al., 1992; Ferrare et al., 1998a,b; Turner et al., 2002; Müller et al., 2007) or by conducting high spectral resolution lidar observations (Shipley et al., 1983; Liu et al., 2002; Hair et al., 2008; Burton et al., 2012; Groß et al., 2013). Usage of approaches with non-elastic observations result in significant enhancement of the information contents in backscattering observations, which allows derivation of aerosol extinction profiles and even estimations of aerosol microphysical properties without a priori constraints on aerosol type or loading (Müller et al., 1999, 2005; Veselovskii et al., 2004). Despite of the achieved progress in non-elastic lidar technology (Baars et al., 2009; Althausen et al., 2009) the bulk of monitoring of vertical aerosol variability is conducted by the conventional lidars and the constraining of aerosol type is done using coincident airborne measurements by nephelometers (Hoff et al., 1996; Adam et al., 2004), spectrophotometers (Marenco et al., 1997) or using ground-based measurements by sun photometers (Waquet et al., 2005).

The straightforward constraining of the lidar retrievals using values of total aerosol optical thickness is a common way of utilizing coincident sun-photometer measurements for the improvement of lidar observations processing (Fernald et al., 1972; Fernald, 1984). In addition, several more sophisticated approaches of combining two types of measurements were proposed recently for exploring additional sensitivities in both lidar and photometric observations. Such methods are usually aimed not only at improving accuracy of the retrieved aerosol characteristics, but rather at retrieving qualitatively new aerosol information. For example, the most common lidar products include vertical profiles of extinction or/and concentration of aerosols that are derived using a lidar ratio fixed under some assumptions about aerosol type, 
and coincident data from sun photometers could provide the required information about aerosol type. However, aerosol type may change vertically, for example, when background aerosol is mixed with layers of transported aerosols as those from desert dust or biomass burning aerosols. Ground-based radiometric data have practically no sensitivity to vertical variability of aerosol; they can only provide some indication of possible aerosol mixtures. On the other hand, spectral (sensitive to variations of aerosol sizes) and polarimetric (sensitive to particle shape) lidar measurements can trace a rather clear qualitative picture of vertical variability of aerosol properties. Utilization of such lidar data in a combination with coincident radiometric data allows some quantitative description of vertical distribution of aerosol mixtures.

Generally, information about sizes and composition of aerosol particles obtained from radiometers is used for defining a number of different aerosol components and their detailed properties (size distributions, complex refractive index and particle shape). Then lidar data are fitted using optical properties of these assumed aerosol components by searching for their vertical mixture that provides the best match of lidar data. For example, studies by Chaikovsky et al. (2002, 2004, 2006a, 2012) and Cuesta et al. (2008) used the measured spectral dependence of backscatter and extinction to derive vertical distribution of two optically distinct aerosol modes assuming that only concentrations of the each aerosol mode can change vertically. The size distributions and complex refractive indices of each aerosol component were fixed using the aerosol retrievals from AERONET radiometers. In the LiRIC (Lidar/Radiometer Inversion Code) algorithm Chaikovsky et al. (2012) assumed two mono-modal fine and coarse aerosol components with the size distributions obtained by dividing AERONET derived distribution into two using the minimum in the range of sizes from 0.194 to $0.576 \mu \mathrm{m}$ as a separation point. The complex refractive index for both modes was assumed the same and equal to the one retrieved by the AERONET. Cuesta et al. (2008) used more complex procedure. First, the AERONET size distribution was decomposed into log-normal mono-modal distributions. Then both bi-modal size distributions of each mode and complex refractive indices were defined using available ancillary data. Ansmann et al. (2011b) used measured depolarization profiles in order to derive vertical distribution of spherical and non-spherical aerosol components with size distributions and complex refractive indices fixed from modelling. Also Sinyuk et al. (2008) have proposed retrieval of both columnar and vertical aerosol properties by inverting a combined data from coincident observations by CALIPSO satellite lidar and AERONET radiometers.

The GARRLiC (Generalized Aerosol Retrieval from Radiometer and Lidar Combined data) approach proposed in this paper pursues even deeper synergy of lidar and radiometer data in the retrievals. Indeed, the methods described above are aimed at enhanced processing of lidar data and do not include any feedback on aerosol columnar properties. At the same time, some additional sensitivity to columnar properties of aerosol compared to radiometric data is provided from lidar measurements. For example, the radiometric observations from ground do not include observation in back scattering direction. In addition, the radiation field observed by the radiometers, in particular its polarimetric properties, has some sensitivity to aerosol vertical distribution but usage of this sensitivity is practically impossible without relying on independent information about vertical variability of aerosol. Therefore, the approach proposed here is aimed to take the advantage from all sensitivities in lidar and radiometric data to both vertical and columnar aerosol properties and to combine the benefits of the most powerful approaches to combined lidar/radiometer data treatment.

\section{The GARRLiC algorithm concept}

Both LiRIC and GARRLiC algorithms use positive heritage of the AERONET retrieval. For example, several key elements of the statistically optimized inversion approach designed for AERONET by Dubovik and King (2000) were adapted in LiRIC. In addition, LiRIC uses the identical to AERONET model of aerosol microphysics. At the same time, LiRIC takes its roots from earlier lidar retrievals adopting some elements of the AERONET retrieval. In this regard, GARRLiC was created by direct modification of AERONET and PARASOL algorithms adapting them for inclusion of lidar data. The comparison of the mentioned algorithm inputs is given in Fig. 1. The approach for treating lidar data strongly relies on LiRIC heritage. Therefore, below we will review the key aspects of all these algorithms that are used in the GARRLiC design.

The AERONET operational retrieval is implemented successfully for more than a decade by the algorithm described by Dubovik and King (2000). It had been tested (Dubovik et al., 2000), improved and upgraded over time. For example, the following new modelling aspects have been included: (i) accounting for particle non-sphericity in aerosol scattering (Dubovik et al., 2002b, 2006), (ii) simulation of bidirectional land and ocean surface properties (Sinyuk et al., 2007), and (iii) both modelling of linear polarization and using the polarimetric measurements in the retrieval (Dubovik et al., 2006; Li et al., 2009). Years of the algorithm's exploitation has shown the possibility to provide new valuable details of aerosol properties (e.g. Dubovik et al., 2002a; Eck et al., 2005, 2012, etc.). The algorithm by Dubovik and King (2000) has been developed with the idea to achieve high flexibility in using the various observations and deriving the extended set of aerosol parameters. Specifically, the algorithm is based (see Dubovik and King, 2000; Dubovik, 2004) on multi-term LSM (least square method) that allows flexible and rigorous inversion of the various combinations of the independent multi-source measurements. As a result, the modifications of the algorithm have been used for inverting the 


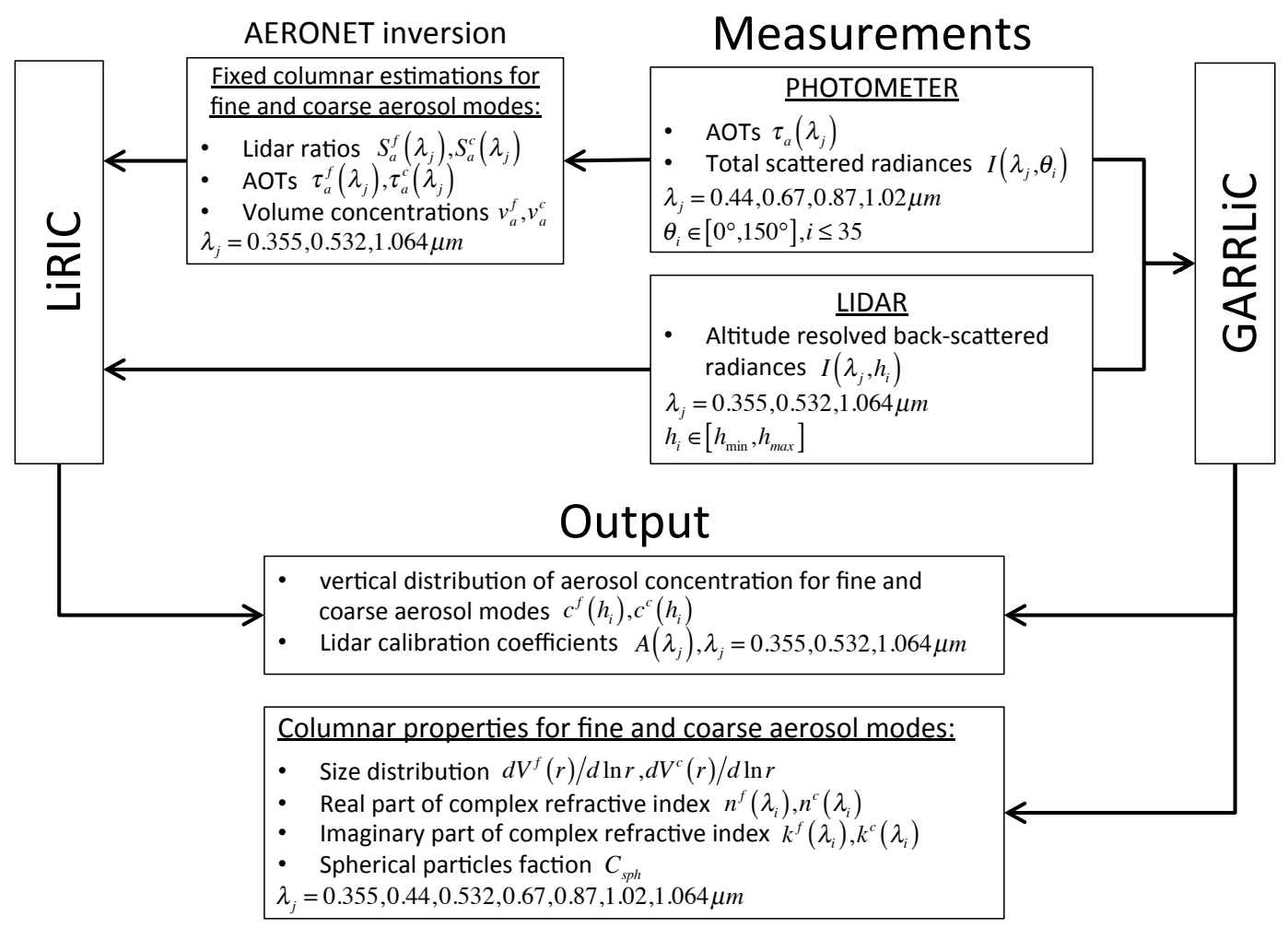

Fig. 1. Comparison of LiRIC and GARRLiC algorithms.

various combined data. For example, Sinyuk et al. (2007) used a modified algorithm for deriving both aerosol and surface properties from coincident ground-based radiometer and satellite observations. Gatebe et al. (2010) have implemented a modification for inverting the combination of the groundbased AERONET observations with the airborne observations by the photometer and up- and down-looking radiometer and derived the detailed properties of aerosol both over and under the airplane together with properties of surface reflectance. The latest modification of the algorithm has been developed by Dubovik et al. (2011) for retrieving both properties of aerosol and surface from observations of PARASOL/POLDER. This version of the algorithm generalizes and includes most of precedent modifications. Moreover, the main part of the computer routine realizing the algorithm has been significantly rewritten with the objective of the enhancing algorithm flexibility in order that it could be used in multiple applications with no or only minor modifications of the main body of the algorithm routine. The algorithm has the nearly independent modules "forward model" and "numerical inversion" (see Fig. 2) in the respect that these modules can be modified independently. Correspondingly, if a possibility of simulating a new measured atmospheric characteristic is included in the "forward model" this characteristic can be inverted with no modifications of the "numerical inversion" module in the source code. Only input parameters of the inversion program need to be changed. As a result, the algorithm by Dubovik et al. (2011) can be used with no modifications in multiple applications. For example, the same program can be used for aerosol retrieval from satellite (e.g. POLDER/PARASOL), ground-based (e.g. AERONET) or aircraft observations. In the present development we used this last version of the algorithm and modified it by adding a possibility to invert lidar observations together with passive radiometric data. With that purpose modelling of lidar observations was included in the "forward model" and the "numerical inversion" module was adapted for inverting the combined radiometer and lidar observations. The details of these modifications are described in two following sections.

\section{Modifications employed in the "forward model"}

The previous versions of the retrieval code (Dubovik and King, 2000; Dubovik et al., 2011) and its modifications (Sinyuk et al., 2007; Gatebe et al., 2010) were developed for inverting only passive observations by ground-based, satellite and airborne radiometers. Therefore, for the needs of the current study a possibility of modelling lidar observations was included into the "forward model" module. The diagram in Fig. 3 illustrates the concept of accounting for the aerosol vertical variability in the "forward model" module of the present algorithm. Although the concept has significant similarities with LiRIC, it has several new aspects. 


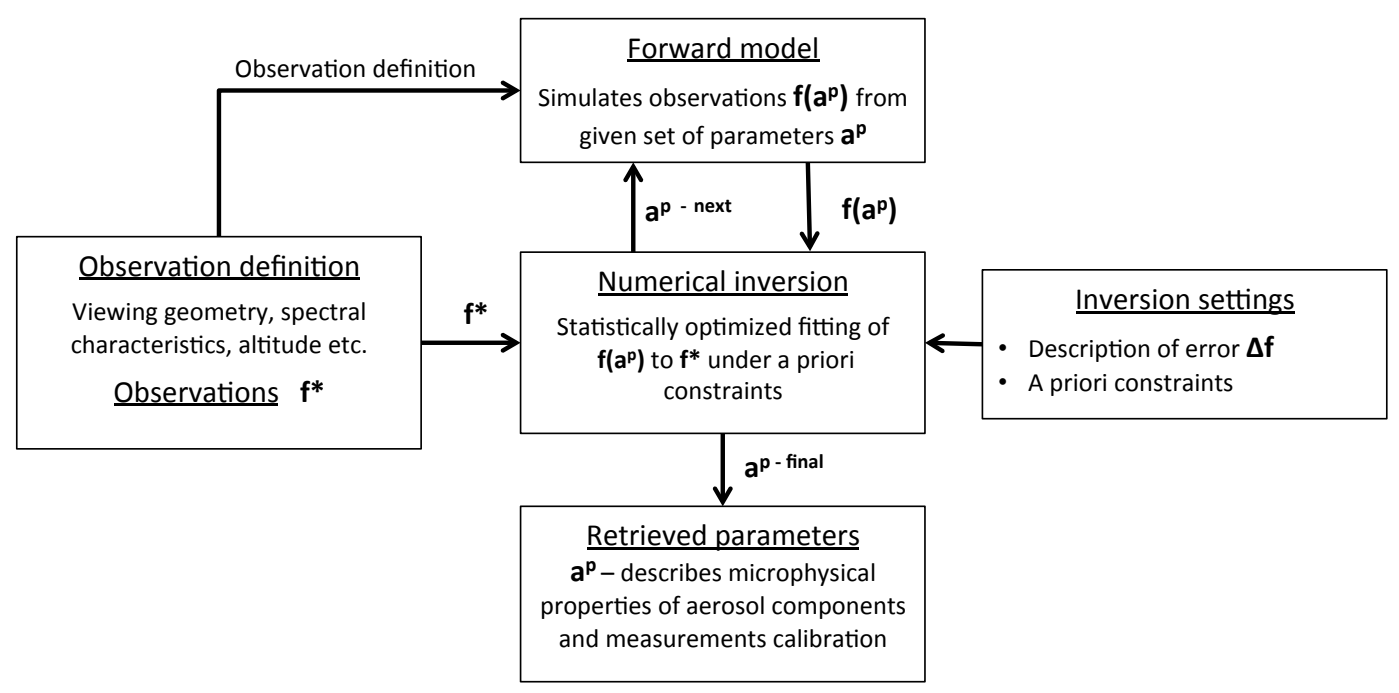

Fig. 2. General structure of the inversion algorithm.

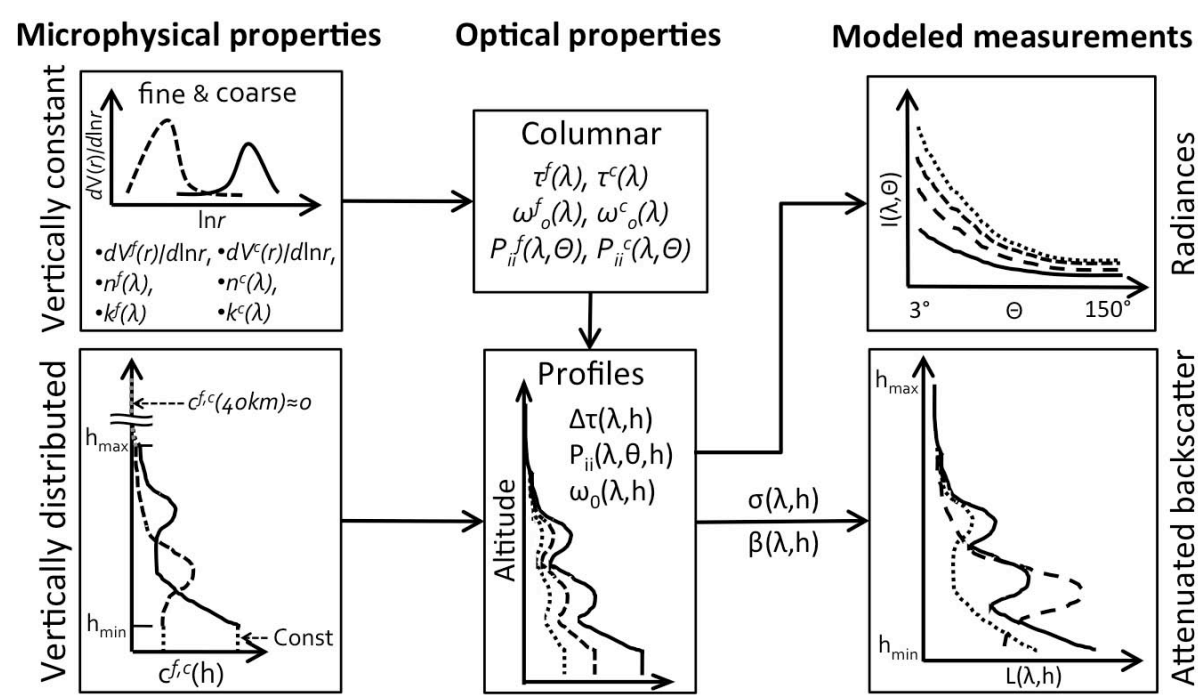

Fig. 3. General scheme of the measurements modelling using a two-component vertically distributed aerosol model.

Similarly to LiRIC, GARRLiC is designed to provide two independent vertical profiles of the concentrations of fine and coarse modes that are among the retrieved characteristics. Aerosol is described as a bi-component mixture of fine and coarse aerosol modes. The microphysical properties of each mode (particle sizes, complex index of refraction and shape) are height independent, while vertical profiles of concentrations vary with altitude. Such approach minimizes the amount of a priori estimations used in the retrieval, and it is expected to provide more detailed and accurate information about both vertical and columnar aerosol properties. In a contrast to LiRIC, in the GARRLiC model the size intervals of the modes may overlap and the size independent complex refractive index may be different for each aerosol component.

\subsection{Attenuated backscatter}

The attenuated backscatter $L(\lambda, h)$ measured by lidar was modelled in single-scattering approximation using the lidar equation:

$L(\lambda, h)=A(\lambda) \beta(\lambda, h) \exp \left(-2 \int_{0}^{h} \sigma\left(\lambda, h^{\prime}\right) \mathrm{d} h^{\prime}\right)$,

where $A(\lambda)$ is the lidar calibration parameter, $\sigma(\lambda, h)$ is the vertical profile of atmospheric extinction, and $\beta(\lambda, h)$ is the vertical profile of the atmospheric backscattering that is modelled using profiles of atmosphere single-scattering albedo $\omega_{0}(\lambda, h)$ and the phase function $P_{11}(\Theta, \lambda, h)$ at scattering angle $\Theta=180^{\circ}$ as follows: 
$\beta(\lambda, h)=\frac{1}{4 \pi} \sigma(\lambda, h) \omega_{0}(\lambda, h) P_{11}\left(180^{\circ} \lambda, h\right)$.

The extinction and backscattering of the atmosphere are affected by gaseous absorption, molecular scattering and aerosol scattering and absorption:

$\sigma(\lambda, h)=\sigma_{\mathrm{gas}}^{\mathrm{abs}}(\lambda, h)+\sigma_{\mathrm{mol}}^{\mathrm{scat}}(\lambda, h)+\sigma_{\mathrm{aer}}^{\mathrm{ext}}(\lambda, h)$,

$\beta(\lambda, h)=\beta_{\mathrm{mol}}(\lambda, h)+\beta_{\mathrm{aer}}(\lambda, h)$.

The lidar measurements are made in window channels $(0.355,0.532$ and $1.064 \mu \mathrm{m})$ with very minor gaseous absorption that is accounted using known climatological data. The effects of molecular scattering are also accounted by usage of climatological data. Specifically, the phase function $P_{11}^{\mathrm{mol}}\left(180^{\circ} \lambda, h\right)$ of molecular scattering is constant and well known. The variability of a molecular scattering profile $\sigma_{\text {mol }}^{\text {scat }}(\lambda, h)$ over an observation site can be simulated with acceptable accuracy based on the information about site's geographical coordinates and elevation (Fleming et al., 1988, http://ccmc.gsfc.nasa.gov/ modelweb/atmos/cospar1.html). However, the aerosol properties $\sigma_{\text {aer }}^{\text {ext }}(\lambda, h)$ and $\beta_{\text {aer }}(\lambda, h)$ are highly variable and cannot be modelled using climatologies. Therefore, in the "forward model" these properties are driven by the parameters included in the vector of unknowns that are retrieved during inversion. The radiometric observations both from ground and space are mostly sensitive to columnar properties of aerosol; therefore the "forward model" in the previous version of the algorithm was driven by the parameters describing these columnar properties. The aerosol was assumed as a mixture of the several aerosol components. Each aerosol component was represented by a sum of spherical and nonspherical fractions. The spherical fraction was modelled as a polydisperse mixture of the spheres. The non-spherical fraction was modelled as mixture of randomly oriented polydisperse spheroids. The distributions of particle volumes and the complex refractive indices were assumed the same in both spherical and non-spherical aerosol fractions. The extinction, absorption and scattering properties of the aerosol in the total atmospheric column were modelled as

$$
\begin{aligned}
\tau_{\mathrm{ext} / \mathrm{abs}}(\lambda) & =\sum_{k=1, \ldots, N_{k}}\left[\sum _ { i = 1 , \ldots , N _ { i } } \left(c_{\mathrm{sph}} \mathbf{K}_{\mathrm{ext} / \mathrm{sps}}^{\mathrm{sph}}\left(\ldots, r_{i}\right)\right.\right. \\
& \left.\left.+\left(1-c_{\mathrm{sph}}\right) \mathbf{K}_{\mathrm{ext} / \mathrm{abs}}^{\mathrm{ns}}\left(\ldots, r_{i}\right)\right) \frac{\mathrm{d} V_{k}\left(r_{i}\right)}{\mathrm{d} \ln r}\right] \\
\omega_{0}(\lambda) P_{i i^{\prime}}(\Theta, \lambda) & =\sum_{k=1, \ldots, N_{k}}\left[\sum _ { i = 1 , \ldots , N _ { i } } \left(c_{\mathrm{sph}} \mathbf{K}_{i i^{\prime}}^{\mathrm{sph}}\left(\ldots, r_{i}\right)\right.\right. \\
& \left.\left.+\left(1-c_{\mathrm{sph}}\right) \mathbf{K}_{i i^{\prime}}^{\mathrm{ns}}\left(\ldots, r_{i}\right)\right) \frac{\mathrm{d} V_{k}\left(r_{i}\right)}{\mathrm{d} \ln r}\right]
\end{aligned}
$$

where $\mathbf{K}_{\mathrm{ext} / \mathrm{abs}}^{\mathrm{sph}}\left(\ldots, r_{i}\right)$ and $\mathbf{K}_{i i^{\prime}}^{\mathrm{ns}}\left(\ldots, r_{i}\right)$ are the kernels of extinction, absorption and scattering properties of spherical and non-spherical aerosol fractions (Dubovik et al., 2011). For reducing calculation time in the numerical integration of spheroid optical properties over size and shape, these kernels were arranged as the look-up tables simulated for quadrature coefficients employed as discussed in details by Dubovik et al. (2006). The calculations of kernels for nonspherical fraction were done assuming non-spherical aerosol as a mixture of randomly oriented polydisperse spheroids with the distribution of the aspect ratios fixed to the one providing the best fit to the laboratory measurements of mineral dust (feldspar sample) phase matrices by Volten et al. (2001). Such strategy of accounting for non-spherical shape of desert dust aerosol is successfully used in the operational AERONET retrieval.

It is noteworthy that the spheroid model developed by Dubovik et al. (2002b, 2006) appeared to be rather useful for other aerosol remote sensing applications. It was shown that the spheroid model allows qualitative reproduction of the main features of lidar observations of non-spherical desert dust (Cattrall et al., 2005; Schuster et al., 2012). Furthermore, Veselovskii et al. (2010), Di Girolamo et al. (2012) and Müller et al. (2013) have incorporated the spheroid model into the algorithm retrieving aerosol properties from lidar observations, which were, probably, one of the first attempts to interpret quantitatively the sensitivity of the lidar observations to particle non-sphericity. It should be noted that the studies by Müller et al. (2010, 2012) outlined some potential issues in the ability of the spheroidal model to reproduce accurately some specific features of the obtained backscattering observations. More recent comparisons of detailed Raman observations with LiRIC retrievals (based on spheroid model) by Wagner et al. (2013) and with AERONET retrieved columnar aerosol properties by Müller et al. (2013) provided notably more positive conclusions regarding the potential of using spheroids for modelling aerosol backscattering properties. Though uncertainties in interpretation of the lidar observations using spheroids exist, all above studies are in consensus that using spheroids as models of aerosol particles instead of spheres provides significant improvements in interpretation of desert dust observations. Moreover, at present, a polydisperse mixture of spheroids is the only physical model used rigorously in operational aerosol retrievals and, based on accumulated results and experience, there are numerous efforts dedicated to improving the spheroid model or identifying a more accurate alternative model.

It should be noted that Eqs. (5) and (6) are written for aerosol composed by $N_{k}\left(k=1, \ldots, N_{k}\right)$ components, where each component has different values of complex refractive index $n_{k}, k_{k}$ and size distribution $\frac{\mathrm{d} V_{k}\left(r_{i}\right)}{\mathrm{d} \ln r}$. Such possibility of modelling multi-component aerosol is included in the previous version of the algorithm for both inverting ground based (Dubovik and King, 2000) and satellite (Dubovik et al., 2011) observations. In principle, such assumption allows for accurate modelling of scattering by mixtures of aerosols of different types with distinctly different 
indices of the refraction. Such situations often appear in reality, for example, when smoke is mixed with a transported layer of desert dust. The differentiation and retrieval of both the size distributions and the complex refractive indices for each fraction of mixed aerosol from remote sensing is highly demanded and recommended (Mishchenko et al., 2007). However, due to the limited information content of radiometric observation, realizing such retrieval is a very challenging task. For example, sensitivity studies by Dubovik et al. (2000) demonstrated and studied such retrieval in a series of numerical tests with synthetic AERONET data and found that the retrieval of bi-component $\left(N_{k}=2\right)$ aerosol was nonunique. Specifically, using different initial guesses the retrieval algorithm was finding several different bi-component aerosol mixtures providing an equally good fit of the observations. As a result of this feature, the operational AERONET algorithm uses the assumption of mono-component aerosol with size independent complex refractive index. Nonetheless, in the present study we use a bi-component aerosol model, where aerosol is composed by fine $(k=1)$ and coarse $(k=2)$ aerosol components with different size distributions and complex refractive indices. It is expected that a combination of the observations by ground-based radiometer with the spectral lidar observations provide sufficient information for satisfactory retrieval of bi-component aerosol mixture properties. Indeed, the spectral observations of lidar have sensitivity to mixture of aerosol layers at different altitudes. This sensitivity should help to differentiate the properties of a bicomponent mixture.

The vertical variability of the atmosphere is modelled using vertical profiles of the volume concentrations $c_{k}(h)$ of the aerosol components under an assumption that such characteristics as size distribution, complex refractive index and particle shape of each aerosol component are vertically independent. Therefore, aerosol backscattering $\beta_{\text {aer }}(\lambda, h)$ and extinction properties $\sigma_{\text {aer }}(\lambda, h)$ can be modelled as

$\beta_{\text {aer }}(\lambda, h)=\frac{1}{4 \pi} \sum_{k=1,2} \sigma_{\text {aer }}^{k}(\lambda, h) \omega_{0}^{k}(\lambda) P_{11}^{k}\left(180^{\circ}, \lambda\right)$

and

$\sigma_{\text {aer }}^{k}(\lambda, h)=\tau_{k}(\lambda) c_{k}(h)$,

where the vertical profiles of the volume concentrations $c_{k}(h)$ of aerosol components are normalized to unity: $h_{\mathrm{TOA}}$ $\int_{0}^{1} c_{k}(h) \mathrm{d} h=1$.

Thus, this approach is convenient for both modelling columnar aerosol properties by Eqs. (5) and (6) and vertical lidar observations by Eq. (1).

In addition, vertical variability of aerosol may have some effect on the outgoing atmospheric radiances measured from space (Dubovik et al., 2011). This variability is accounted by solving full radiative transfer equations in the plane parallel approximation using vertically dependent optical characteristics of the atmosphere:

$$
\begin{aligned}
& \Delta \tau_{i}=\Delta \tau_{i}^{\mathrm{gas}}+\Delta \tau_{i}^{\mathrm{mol}}+\sum_{k=1,2} \Delta \tau_{i}^{\mathrm{aer}, k}, \\
& \omega_{0}(\lambda)=\frac{\Delta \tau_{i}^{\mathrm{mol}}+\sum_{k=1,2} \Delta \tau_{i}^{\mathrm{aer}, k} \omega_{0}(\lambda)}{\Delta \tau_{i}^{\mathrm{gas}}+\Delta \tau_{i}^{\mathrm{mol}}+\sum_{k=1,2} \Delta \tau_{i}^{\mathrm{aer}, k},} \\
& P_{i i^{\prime}}^{i}(\Theta, \lambda)=\frac{\Delta \tau_{k}^{\mathrm{mol}} P_{i i^{\prime}}(\Theta, \lambda)+\sum_{k=1,2} \Delta \tau_{i}^{\mathrm{aer}, k} \omega_{0}^{k}(\lambda) P_{i i^{\prime}}^{\mathrm{aer}, k}(\Theta, \lambda)}{\Delta \tau_{i}^{\mathrm{mol}}+\sum_{k=1,2} \Delta \tau_{i}^{\mathrm{aer}, k} \omega_{0}(\lambda)},
\end{aligned}
$$

where $\Delta \tau_{i}, \omega_{0}^{i}(\lambda)$ and $P_{i i^{\prime}}^{i}(\Theta, \lambda)$ represent optical properties of $i$-th homogeneous layer of the atmosphere. It should be noted that in the AERONET retrieval algorithm (Dubovik and King, 2000) the accountancy for aerosol vertical variability is also possible. However, the sensitivity studies by Dubovik et al. (2000) show practically no sensitivity to aerosol vertical profile and, as a result, the operational AERONET retrievals are conducted under the assumption of vertically homogeneous atmosphere. The PARASOL aerosol retrieval by Dubovik et al. (2011) accounts for vertical variability of aerosol (similarly as shown in Eq. (8), and is designed to retrieve some information about aerosol vertical distribution. However, the passive radiometric and polarimetric observations from space have very moderate sensitivity to aerosol vertical variability. Therefore, vertical profiles of aerosol concentrations $c_{k}(h)$ in the PARASOL algorithm are approximated by the Gaussian distribution and only the median height of aerosol layer $h_{a}$ is retrieved. In contrast, the profiles $c_{k}(h)$ in the present study are not approximated by any specific function and could have practically arbitrary shapes. Such approach is necessary for adequate modelling of lidar observations. In principle, such accurate accounting for aerosol vertical variability in radiative transfer calculations is not necessary for processing of passive observations, however, this may have some positive effects once radiometric data are combined with lidar observations, as it was done in this study.

\subsection{Adjustments of the "forward model" to model lidar observations}

Theoretically, the profiles $c_{k}(h)$ should describe the variability of aerosol at all altitudes from ground to space. However, the height range of lidar measurements has limitations. Usually ground-based lidar measurements do not cover all atmosphere altitudes and are conducted between the upper $h_{\max }$ and the lower $h_{\min }$ limits. Therefore, the vertical profiles $c_{k}(h)$ can be derived only between these limits and some assumptions about $c_{k}(h)$ for $h>h_{\max }$ and $h<h_{\min }$ should be made in order to describe the vertical distribution of aerosol in the whole atmosphere column which is required for radiative transfer calculations. Here, the aerosol over $h_{\max }$ was 
Table 1. Parameters retrieved by the algorithm.

\begin{tabular}{|c|c|}
\hline \multicolumn{2}{|c|}{ Aerosol characteristics } \\
\hline$\frac{d V^{k}\left(r_{i}\right)}{d \ln r}$ & $\left(i=1, \ldots, N_{i}^{k} ; k=1,2\right)$ values of volume size distribution in size bins of $k$-th aerosol component \\
\hline$c^{k}\left(h_{i}\right)$ & $(k=1,2)$ vertical distribution of aerosol concentration of $k$-th aerosol component, normalized to 1 \\
\hline$C_{\mathrm{sph}}$ & Faction of spherical particles of coarse aerosol component \\
\hline$n^{k}\left(\lambda_{i}\right)$ & $\begin{array}{l}\left(i=1, \ldots, N_{\lambda}=7 ; k=1,2\right) \text { the real part of the refractive index for } k \text {-th aerosol component at every } \lambda_{i} \\
\text { of combined lidar/photometric measurement }\end{array}$ \\
\hline$k^{k}\left(\lambda_{i}\right)$ & $\begin{array}{l}\left(i=1, \ldots, N_{\lambda}=7 ; k=1,2\right) \text { the imaginary part of the refractive index for } k \text {-th aerosol component at every } \lambda_{i} \\
\text { of combined lidar/photometric measurement }\end{array}$ \\
\hline \multicolumn{2}{|c|}{ Lidar calibration parameters } \\
\hline$A\left(\lambda_{i}\right)$ & $(i=1, \ldots, 3)$ Lidar calibration coefficient at each $\lambda_{i}$ of the lidar measurement \\
\hline
\end{tabular}

assumed exponentially, decreasing from $c_{k}\left(h_{\max }\right)$ to a value close to zero $\left(10^{-30}\right)$ on the top of the atmosphere $h_{\mathrm{TOA}}$, and under $h_{\min }$ it was assumed constant and equal to the lowest estimated point $c_{k}\left(h_{\min }\right)$ as the following:

$c(h)=c\left(h_{\min }\right), h \leq h_{\min }$

$c(h)=c\left(h_{\max }\right) \exp (-\alpha h), h>h_{\max }$,

where $\alpha$ is chosen from the condition that $c_{k}\left(h_{\mathrm{TOA}}\right) \rightarrow 0$.

The actual lidar observations used in the present study had an altitude range from 0.5 up to $10 \mathrm{~km}$, with the altitude resolution $\Delta h$ of $15 \mathrm{~m}$, which provides information about aerosol backscatter properties in $N_{h} \simeq 600$ altitude points $h_{i}$. In order to avoid an excessively high number of the retrieved parameters in the algorithm $N_{h}$ was limited to a smaller number (60). Since air density decreases exponentially and a similar scale is expected for the variability of aerosol profiles, the logarithmically equidistant ( $\Delta \ln h=$ Const) $h_{i}$ have been chosen for describing profiles $c_{k}(h)$ in the algorithm.

The lidar measurements $L(\lambda, h)$ were also scaled down from $N_{h} \simeq 600$ to a smaller number. This decreases calculation time, and in addition, helps to decrease the effect of high frequency noise. Since the power of the laser pulse returned to a receiver decreases as square of the distance during beam propagation in the atmosphere the level of noise strongly increases with the altitude. Therefore, the decimation of lidar signals in logarithmic scale over altitude provides practically useful noise suppression. Since lidar signal is measured with constant vertical resolution ( $\Delta h=$ Const), the decimation in logarithmic scale results in a decrease of sampling rate with the increase of altitude. According to the Kotelnikov-Nyquist theorem (Nyquist, 1928; Kotelnikov, 1933) the lower sampling rate at high altitudes decreases the amplitudes of high frequency oscillations, which usually are attributed to noise. The described decimation method could be considered as an expanding sliding window low pass filter, allowing efficient noise suppression without loss of significant information about aerosol vertical structure.

\subsection{The calibration of lidar signal}

Commonly, retrievals use the attenuated backscatter (Eq. 1) normalized by attenuated backscatter at the reference altitude $h_{\text {ref }}$. This reference altitude is chosen from the altitudes higher than $h_{\max }$, assuming that amount of the aerosol over that altitude is negligible, i.e.

$$
\begin{aligned}
& L\left(\lambda, h_{\text {ref }}\right)=\beta_{\text {mol }}\left(\lambda, h_{\text {ref }}\right) \times \exp \\
& \quad\left(-2\left(\tau^{\text {aer }}(\lambda)+\int_{h_{0}}^{h_{\text {ref }}}\left(\sigma_{\text {gas }}\left(\lambda, h^{\prime}\right)+\sigma_{\mathrm{mol}}\left(\lambda, h^{\prime}\right)\right) \mathrm{d} h^{\prime}\right)\right) .
\end{aligned}
$$

Correspondingly if $\tau^{\text {aer }}(\lambda)$ is known the above attenuated backscattering at the reference altitude $h_{\text {ref }}$ can be easily calculated. However, due to the high presence of noise at high altitudes the selection of the reference point remains a manual procedure that influences lidar retrievals (Kovalev and Oller, 1994; Matsumoto and Takeuchi, 1994). To address this problem Chaikovsky et al. (2004) have introduced the "calibration coefficient" $A(\lambda)$ in Eq. (1) and included this value into the set of the retrieved parameters. If the error is small $A(\lambda) \rightarrow 1$. Here we follow the same concept and derive $A(\lambda)$ together with the other unknowns (see the list of the retrieved parameters in Table 1).

\section{4 "Numerical inversion" organization}

The retrieval is organized as a multi-term LSM fitting similarly to the previous developments (Dubovik and King, 2000; Dubovik, 2004; Dubovik et al., 2011). This approach has shown to be convenient for designing efficient inversions of combined complex data sets (Sinyuk et al., 2007; Gatebe et al., 2010). This approach considers an inversion as a statistically optimized simultaneous solution of a system of several independent equations:

$f_{k}^{*}=f_{k}(a)+\Delta_{k}\left(k=1,2, \ldots, N_{k}\right)$, 
where $f_{k}^{*}$ are the data from different sources; i.e. $f_{k}^{*}$ are the estimations of the characteristics $f_{k}(a)$. Since these estimations are originated from different sources their errors $\Delta_{k}$ are independent. Correspondingly, under the assumption of the Gaussian distribution of errors $\Delta_{k}$ the optimum solution is provided by multi-term LSM corresponding to a minimum of the quadratic form $\Psi(a)$ defined as

$2 \Psi(a)=\sum_{k=1}^{N_{k}}\left(f_{k}^{*}-f_{k}(a)\right)^{T} \mathbf{C}_{k}^{-1}\left(f_{k}^{*}-f_{k}(a)\right) \rightarrow \min$,

where $\mathbf{C}_{k}$ are covariance matrices of the errors $\Delta_{k}$. According to the suggestion of earlier studies (Dubovik and King, 2000 , etc.) the above condition can be conveniently reformulated using weighting matrices $\mathbf{W}_{k}=\frac{1}{\varepsilon_{k}^{2}} \mathbf{C}_{k}\left(\varepsilon_{k}^{2}\right.$ is the first diagonal element of $\mathbf{C}_{k}$ ):

$2 \Psi(a)=\sum_{k=1}^{N_{k}} \frac{\varepsilon_{0}^{2}}{\varepsilon_{k}^{2}}\left(f_{k}^{*}-f_{k}(a)\right)^{T} \mathbf{W}_{k}^{-1}\left(f_{k}^{*}-f_{k}(a)\right) \rightarrow \min ,($

where $\varepsilon_{0}^{2}$ is first diagonal element of $\mathbf{C}_{k=1}$ - covariance matrix of the data set corresponding to $k=1$. Correspondingly, the contribution of each term in Eq. (16) is scaled by the ratios of error variances $\frac{\varepsilon_{0}^{2}}{\varepsilon_{k}^{2}}$. As outlined by Dubovik and King (2000) this coefficient can be considered as the Lagrange multiplier used in the constrained inversion techniques. In addition, in a case when noise properties are assumed correctly, the achieved minimum can be used for estimating $\varepsilon_{0}^{2}$ as

$$
\left(\Psi(a) \varepsilon_{0}^{2}\right)_{\min } \rightarrow \varepsilon_{0}^{2} .
$$

Additionally, in previous studies (Dubovik and King, 2000; Dubovik, 2004; Dubovik et al., 2011) the data both obtained from actual observations and from a priori knowledge are considered equally in equation system (Eq. 14). Such consideration allows convenient interpretation of a priori constraints and development of flexible retrieval formalism with use of multiple constraints. Specifically, for the convenience of interpretation of the present algorithm, the quadratic form (Eq. 16) can be represented by two terms:

$$
\begin{aligned}
2\left(\Psi(a) \varepsilon_{0}^{2}\right) & =\sum_{k=1}^{N_{\text {meas }}} \frac{\varepsilon_{0}^{2}}{\varepsilon_{k}^{2}}\left(f_{k}^{*}-f_{k}(a)\right)^{T} \mathbf{W}_{k}^{-1}\left(f_{k}^{*}-f_{k}(a)\right) \\
& +\sum_{p=1}^{N_{\text {prior }}} \frac{\varepsilon_{0}^{2}}{\varepsilon_{p}^{2}}\left(s_{p}^{*}-s_{p}(a)\right)^{T} \mathbf{W}_{p}^{-1}\left(s_{p}^{*}-s_{p}(a)\right) .
\end{aligned}
$$

Here, the first group unites $N_{\text {meas }}$ sets of independent measurements (with different level of accuracies) and the second represents a priori constraints. It unites $N_{\text {prior }}$ sets of known a priori data sets $\left(s_{p}^{*}\right)$ used as a priori values of characteristics $s_{p}(a)$. The measurements group has $N_{\text {meas }}=5$ and includes $(k=1)$ AERONET spectral and angular measurements of atmospheric sky-radiances, $(k=2)$ AERONET spectral measurements of aerosol optical thickness and $(k=3, \ldots, 5)$ lidar spectral measurements of attenuated backscatter. Thus, compared to the AERONET retrieval (Dubovik and King, 2000) the measurement group in Eq. (18) includes additional terms corresponding to the measurements of attenuated backscatter at different wavelengths.

It should be noted that in many practical situations the observations are uncorrelated and provide equally accurate data, i.e. weighting matrices are equal to unity matrices $\mathbf{W}_{k}=\mathbf{I}$. Such weight matrix structure directly applicable to the passive measurements both for sky radiances and aerosol optical thickness performed at different wavelengths. However such estimations that were implied in the AERONET and POLDER retrievals are not applicable to lidar measurements, as their variances depend both on the altitude and on the wavelength. Thus the weight matrix of lidar measurement will have a form of diagonal matrix that describes relative altitude dependence of the variance for the given spectral channel:

$\mathbf{W}_{\lambda \ldots}=\frac{1}{\varepsilon_{\lambda \ldots}^{2}}\left(\begin{array}{cccc}C_{\lambda \ldots}\left(h_{\min }\right) & 0 & 0 \\ 0 & \ddots & 0 \\ 0 & 0 & C_{\lambda_{\ldots}}\left(h_{\max }\right)\end{array}\right)$,

where $\varepsilon_{\lambda}^{2}$ is the minimum diagonal element of covariance matrix $\mathbf{C}_{\lambda} \ldots$ whose elements are defined similar with the approach proposed for LiRIC (Chaikovsky et al., 2006a; Denisov et al., 2006; Chaikovsky et al., 2012):

$$
\begin{aligned}
C_{\lambda_{j}}\left(h_{i}\right) & =v^{2}+\frac{g^{2}+q^{2} P^{*}\left(h_{i}, \lambda_{j}\right)}{A M\left(P^{*}-B^{*}\left(\lambda_{j}\right)\right)^{2}} \\
& +\frac{u^{2}}{\left(P^{*}-B^{*}\left(\lambda_{j}\right)\right)^{2}}+4 \alpha_{1}^{2}+4 \alpha_{2}^{2},
\end{aligned}
$$

where $P^{*}\left(\lambda_{j}, h_{i}\right)$ is recorded during lidar measurements, $B^{*}\left(\lambda_{j}\right)$ is the background noise estimation, $A$ is the number of lidar profiles used for the time averaging, $M$ is the number of the lidar signal counts in the altitude-averaging interval, $g$ is the total deviation of the dark current and noise in receiving channel, $q$ is the index that characterizes fluctuation noise of the photo receiver and could be estimated on dark measurements of the photo-receiving module, $u$ is the coefficient that characterizes the amplitude of synchronous noise in receiving channel, $v$ is the non-linearity parameter; $\alpha_{1}$ and $\alpha_{2}$ are the relative errors of molecular optical thickness and backscatter coefficient estimations. Parameters $g$, $q, u$, and $v$ are system dependent and estimated from testing of the lidar registration system, and parameters $\alpha_{1}$ and $\alpha_{2}$ are known for the used model of molecular atmosphere (Fleming et al., 1988, http://ccmc.gsfc.nasa.gov/modelweb/ atmos/cospar1.html). The second group in Eq. (18) unites $N_{\text {prior }}$ sets of known a priori derivatives of the aerosol characteristics. Specifically, we used the derivatives of retrieved size distributions $\mathrm{d} V_{f, c}(r) / \mathrm{d} \ln r$, the complex refractive indices spectral dependencies $n_{f, c}(\lambda)$ and $k_{f, c}(\lambda)$, and the vertical variability of profiles $c_{f, c}(h)$. In order to avoid 
unrealistic oscillations of retrieved aerosol parameters, we assume that a priori values of $s_{p}$ are zeros, i.e. $s_{p}^{*}=0$ and Eq. (18) can be written as

$$
\begin{aligned}
2\left(\Psi(a) \varepsilon_{0}^{2}\right) & =\sum_{k=1}^{N_{\text {meas }}} \frac{\varepsilon_{0}^{2}}{\varepsilon_{k}^{2}}\left(f_{k}^{*}-f_{k}(a)\right)^{T} \mathbf{W}_{k}^{-1}\left(f_{k}^{*}-f_{k}(a)\right) \\
& +\sum_{p=1}^{N_{\text {prior }}} \frac{\varepsilon_{0}^{2}}{\varepsilon_{k}^{2}} a \mathbf{S}_{p}^{T} \mathbf{S}_{p} a^{T},
\end{aligned}
$$

here matrix $\mathbf{S}_{p}$ represents coefficients for calculating finite differences used to estimate the derivatives. The explicit form of these matrices is given in Dubovik (2004) and Dubovik et al. (2011). Thus, compared to the AERONET algorithm the a priori constraint group uses limitations on the derivatives of vertical profiles of aerosol concentrations. Additionally, in the present algorithm we use the limitation on the derivatives separately for $\mathrm{d} V_{f, c}(r) / \mathrm{d} \ln r, n_{f, c}(\lambda)$ and $k_{f, c}(\lambda)$ for both fine and coarse modes. As a result, the algorithm used $N_{\text {prior }}=8$ complementary a priori constraints.

It should be noted that limitations of the derivatives of the vertical profiles appears to be a rather useful and very logical approach to avoid unrealistic spiky vertical variations in profiling that is also used in the LiRIC algorithm by Chaikovsky et al. (2002). Surprisingly, such apparently natural constraining is rarely used in profiling techniques (with few exceptions: Dubovik et al., 1998; Oshchepkov et al., 2002). For example, even the cornerstone methodological studies of atmosphere profiling (e.g. Rodgers, 1976) propose limiting directly the values of profile using a priori estimations. Such approach is generally rather restrictive and can lead to the notable biases in the retrieval in the case when a priori assumed profiles are significantly different from the real ones. For example, in the aerosol microphysical applications where aerosol size distributions are retrieved from the measurements of spectral and angular scattering such approach appears to be unfruitful. Indeed, the shape and magnitudes of aerosol size distribution may strongly vary and direct restriction of its magnitude by a priori values is too restrictive. As a result, although the use of a priori estimates as a constrain in the retrieval of size distribution was proposed and tried by Twomey (1963) much earlier than in atmospheric profiling (e.g. Rodgers, 1976) it was never widely used. Instead, most of established aerosol retrieval algorithms (e.g. King et al., 1978; Nakajima et al., 1983, 1996; Dubovik et al., 1995; Dubovik and King, 2000, etc.) use the limitations of derivatives of aerosol size distribution. Such limitations are obviously more universal and do not have apparent dependence on aerosol type, loading, etc. The same property of derivatives constraining seems to be very advantageous for constraining vertical profile retrievals (as it was done in the present work).

The actual minimization of Eq. (21) in the present algorithm is performed in exactly the same way as described by Dubovik et al. (2011) for "single-pixel" retrieval scenario.

\section{GARRLiC algorithm functionality and sensitivity tests}

Series of sensitivity tests have been performed to verify the performance of the developed algorithm and to provide the illustration of capabilities and limitations of the algorithm to derive a set of aerosol parameters (see Table 1) from coincident lidar and sun-photometer observations.

The sensitivity tests had been designed to conform with realistic conditions of each of the measurements. The tests were carried out for two cases representing situations when desert dust is mixed with urban pollution and biomass burning aerosols. Six different scenarios were considered for the each mixture. Among them 3 scenarios were performed for high aerosol loading with total AOT of $\tau_{a}^{0.532}=1$ and 3 with very low AOT of $\tau_{a}^{0.532}=0.05$ at $\lambda=0.532 \mu \mathrm{m}$. These two situations where chosen from the following considerations. At the high aerosol loading we expect that synergetic retrieval would maximally benefit from information from radiometric observations, while at very low AOT, the lidar data should provide maximum benefits. Indeed, the accuracy of AERONET retrievals is generally higher at high aerosol loading and significantly falls at very low AOT (Dubovik et al., 2000). In contrast, the lidar data remain reliable even at low aerosol loadings. For both high and low aerosol loading cases, three different cases of fine/coarse mode partition were modelled: $\tau_{f} / \tau_{c}=4$, $\tau_{f} / \tau_{c}=1$ and $\tau_{f} / \tau_{c}=0.25$. Thus, resulting in six mixture scenarios: $\tau_{f}=0.8, \tau_{c}=0.2, \tau_{f}=\tau_{c}=0.5, \tau_{f}=0.2, \tau_{c}=0.8$ and $\tau_{f}=0.04, \tau_{c}=0.01, \tau_{f}=\tau_{c}=0.025, \tau_{f}=0.01, \tau_{c}=0.04$ correspondingly.

For each of the six scenarios, two series of the tests were made: (i) tests to estimate the sensitivity to random noise were made without any noise added and with random noise added to the simulated measurements, and (ii) tests to illustrate the possible improvements introduced by using both radiometric and lidar measurements in comparison with the standard AERONET inversion.

\subsection{Description of aerosol and noise models used for sensitivity study}

Two log-normal size distributions were used to generate 25 size bins (10 for fine and 15 for coarse aerosol modes). To make the size distributions directly comparable with actual AERONET observations the values of the generated bin radii were chosen corresponding to the ones of the standard AERONET retrieval. The values used to model size distributions of fine and coarse modes (see Table 2) were taken from the AERONET retrieval climatology corresponding to desert dust and biomass-burning aerosols (Dubovik et al., 2002a).

The values of complex refractive indices at $\lambda=0.44$, $0.67,0.87$ and $1.02 \mu \mathrm{m}$ for "urban pollution", "biomass burning" and "desert dust" aerosol models were adapted from actual long-time observation statistics over the GSFC 
Table 2. Parameters of log-normal distributions used for aerosol size distribution modelling.

\begin{tabular}{llllccc}
\hline Aerosol mode & $r_{\min }, \mu \mathrm{m}$ & $r_{\max }, \mu \mathrm{m}$ & $r_{\text {mean }}, \mu \mathrm{m}$ & $r_{\text {std }}$ & $\tau,\left(\tau_{\text {total }}=1\right)$ & $\tau,\left(\tau_{\text {total }}=0.05\right)$ \\
\hline Fine & 0.05 & 0.576 & 0.148 & 0.4 & $0.8,0.5,0.2$ & $0.04,0.025,0.01$ \\
Coarse & 0.355 & 15.0 & 2.32 & 0.6 & $0.2,0.5,0.8$ & $0.01,0.025,0.04$ \\
\hline
\end{tabular}
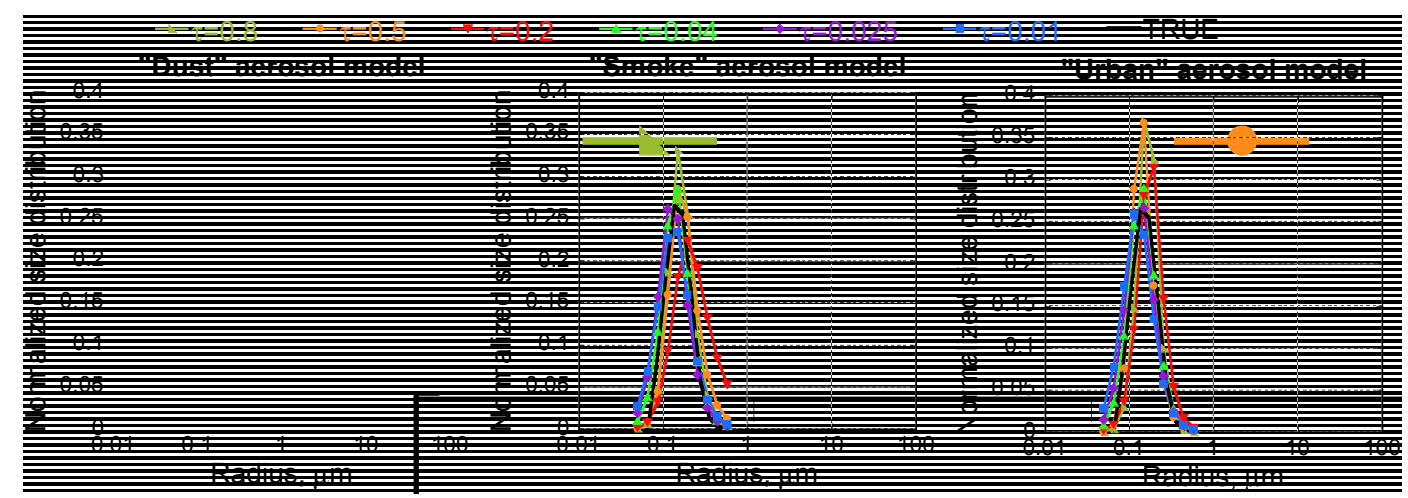

Fig. 4. Retrievals of size distributions of "Dust", "Smoke" and "Urban" aerosol models under different AOT.

(Goddard Space Flight Center), Banizombou and Solar Village AERONET sites correspondingly, where the listed types of the aerosols usually dominate in aerosol load (Dubovik et al., 2002a). The values for spectral channels $\lambda=0.355,0.532$ and $1.064 \mu \mathrm{m}$ corresponding to lidar measurements were obtained by the extrapolation.

Each of the aerosol components was modelled as a mixture of polydisperse spheres and spheroids following Eqs. (5) and (6) with faction of spherical particles $\left(C_{\mathrm{sph}}\right)$ of $10 \%$, the faction of non-spherical particles was $90 \%$ correspondingly. The same $C_{\text {sph }}$ for coarse and fine aerosol modes was chosen due to the limited sensitivity of the measurements to the shape of smaller particles.

Two scenarios with clear vertical separation of fine and coarse aerosol components were used. The fine mode was assumed to represent the background aerosol with specific vertical distribution, while coarse mode distribution had a thick layer approximately at $3 \mathrm{~km}$. Both modes had a significant amount of aerosol in the layers close to the ground and monotonous decrease over the altitude. Such distributions were chosen to mimic the particularities of aerosol vertical distribution usually found in the real lidar observations.

The values of the complex refractive indices, size distributions as well as vertical distribution profiles of the aerosol models could be found marked as "TRUE" in Figs. 4-9.

To model realistic measurement conditions the random normally distributed noise was added to the generated measurements. The variance of noise in optical thickness measurement was set as 0.005 , and the variance of noise in scattered irradiance was chosen as $3 \%$, i.e. $\frac{\Delta I}{I}=0.03$; spectral and altitude dependent variances of lidar measurements were defined as

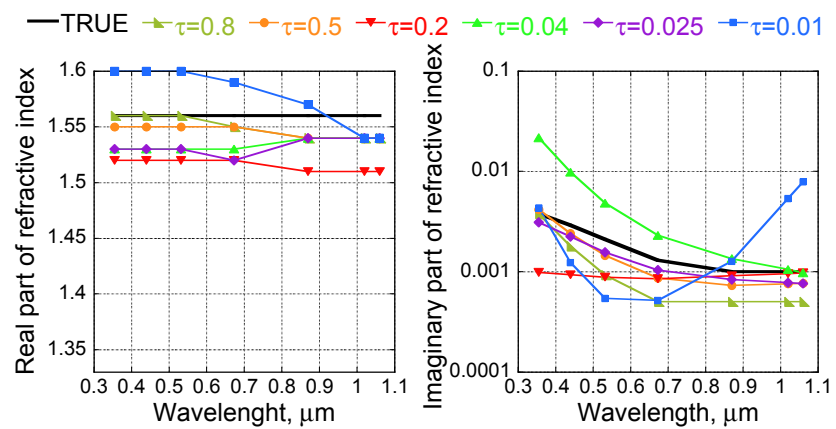

Fig. 5. Retrievals of complex refractive index of the "Dust" aerosol model under different AOT.

$\frac{\Delta L(\lambda, h)}{L(\lambda, h)}=\varepsilon(\lambda) n(h)$,

where $\varepsilon(\lambda)=0.2,0.15$ and 0.1 for $\lambda=0.355,0.532$ and $1.064 \mu \mathrm{m}$, correspondingly, and vertical dependence was set as the following function:

$n(h)=1, \log (h)<1$,

$n(h)=\log (h), \log (h) \geq 1$.

Using the above described microphysical model the synthetic AERONET and lidar measurements were simulated and then inverted. The results were compared with the "assumed" properties.

\subsection{Sensitivity test results}

The discussion of the sensitivity study results will focus on the retrievals of the aerosol properties that were not part of 

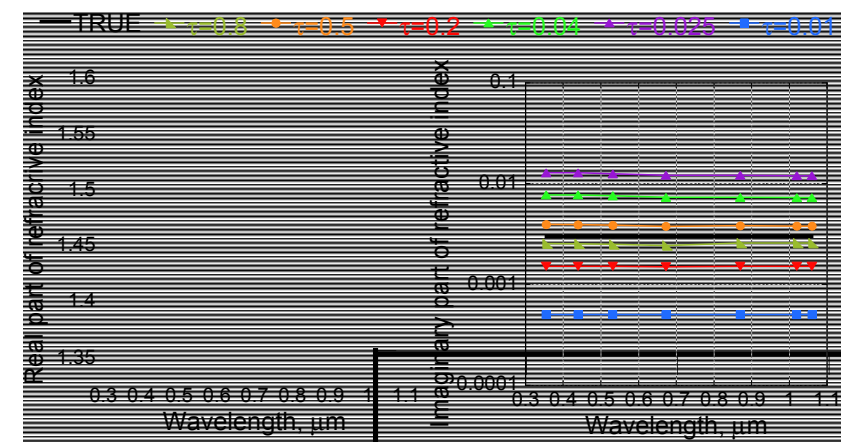

Fig. 6. Retrievals of complex refractive index of the "Urban" aerosol model under different AOT.

the standard AERONET inversion. Specifically, we will pay particular attention to the retrieval of aerosol vertical profiles and differentiation between the properties of fine and coarse aerosol mode parameters including complex refractive indices, size distributions, etc. The results of the sensitivity tests are presented in Figs. 4-9. These results show that the algorithm derives all aerosol parameters with good accuracy, and clearly distinguishes both aerosol modes. The addition of the realistic random noise did not dramatically affect the retrieval results, although once noise is added the retrieval results depart further from the "assumed" values. In addition, we would like to note that the accuracy of aerosol size distribution retrieval is not discussed here. The results of our sensitivity tests show generally very similar tendencies as observed in earlier studies by Dubovik et al. (2000). However, Fig. 4 shows the retrievals of size distributions of aerosol components under different aerosol loads in the presence of random noise for a more descriptive presentation of the sensitivity study.

Figures 5-7 show the retrievals of aerosol complex refractive indices of each aerosol component under noisy conditions performed for six different AOTs and obtained for two aerosol mixtures listed above. As it is seen in Figs. 5-7, the method shows higher accuracy of columnar property retrieval in the cases with higher aerosol loadings. A similar tendency is observed for the retrieval of vertical profiles.

Another observed trend is that the accuracy of the retrievals of complex refractive index for each aerosol mode strongly correlates with the contribution of this mode to the signal. Specifically, the two following tendencies are observed. First, the higher relative contribution of the aerosol mode into the total optical thickness the better is the accuracy in the retrieval of the optical properties of this aerosol mode. Second, the retrieval error of the refractive index increases from shorter wavelengths to longer ones for the fine mode. The tendency for the coarse mode is opposite. Such behaviour could be explained by the fact that the efficiency of scattering by small particles reaches the maximum values when the size parameter is comparable with the wavelength, thus scattering of small particles is more pronounced at the
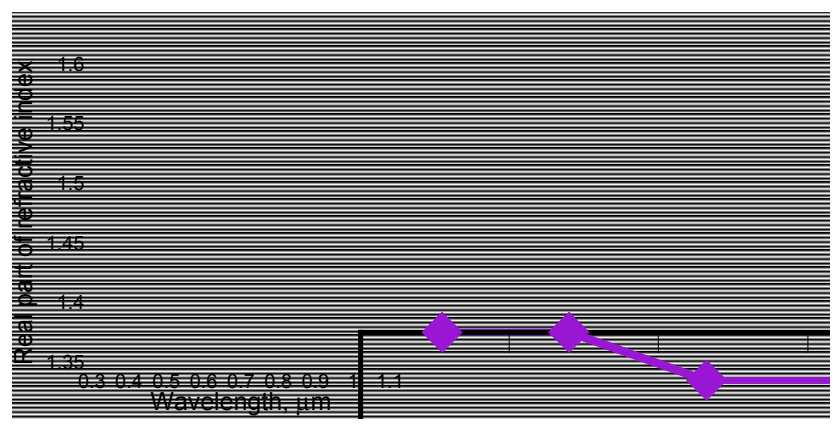

Fig. 7. Retrievals of complex refractive index of the "Smoke" aerosol model under different AOT.

short wavelengths, and scattering of the big particles is more pronounced at long ones.

Figure 8 illustrates that a similar tendency is observed for the retrievals of single-scattering albedo. This trend is especially evident in the situations with low total AOT and when of one of the components dominates. As can be seen in Fig. 8, in such situation retrieval errors of the properties of minor aerosol mode become unacceptably high. This leads to incorrect separation of the total single-scattering albedo between these two aerosol components at shorter wavelengths. The retrievals of total single-scattering albedo depend on the total optical thickness similarly as observed by Dubovik et al. (2000). The scenario with high total AOT and equal partition between the modes is the most favourable for overall retrieval.

Figure 9 shows the retrievals of vertical distributions. As can be seen from these plots the algorithm gives generally adequate vertical profiles for both modes. At the same time, it tends to slightly overestimate the amount of the fine mode and to underestimate coarse mode content in the layers that contain the mixture of aerosols of both types. However, the algorithm always provides adequate total extinction estimations for the given layer.

This tendency remains even in noise free conditions, yet having less drastic scales. It probably can be explained by insufficient information content for the perfect separation of fine and coarse mode contributions to the total lidar signal in the mixed layers.

Another tendency observed in the sensitivity study is lower sensitivity of the retrieval to the properties of the fine mode, especially to the complex refractive index. These high errors in derived complex indices of refraction propagate to the estimations of other optical properties of fine mode. The trend is less pronounced in situations with high aerosol loading in noise free conditions. Figure 10 showing the dependence of lidar ratios of fine and coarse modes on the complex refractive index for particles of different shape indicates that the fundamental reason for this feature is a selective sensitivity of the lidar measurement to the optical properties of the particles of different size and shape. Values of lidar ratios 

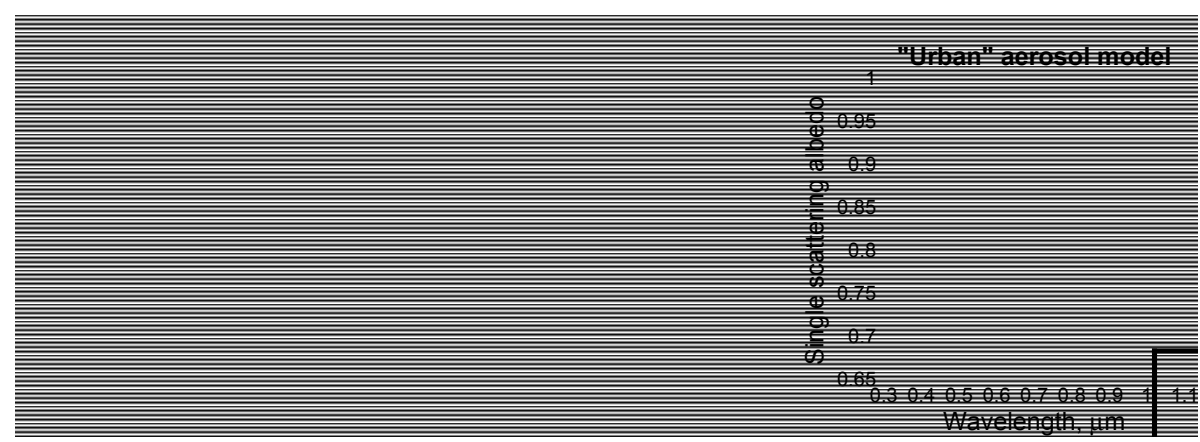

Fig. 8. Retrievals of the single-scattering albedo of aerosol components under different AOT.
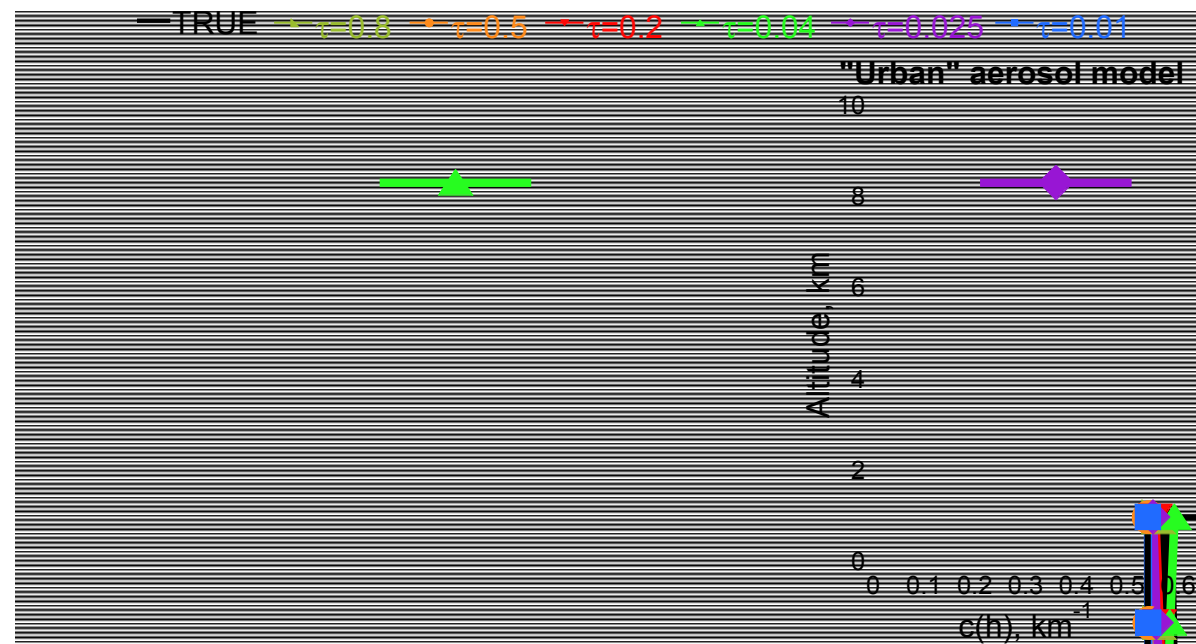

Fig. 9. Retrievals of the vertical distributions of aerosol components under different AOT.

depicted in Fig. 10 were retrieved using size distributions mentioned in Table 2 with corresponding optical thickness of $\tau_{f}=\tau_{c}=0.5$. To retrieve the lidar ratios of spherical and non-spherical particles parameter $C_{\mathrm{sph}}$ was set to 100 and $0 \%$ correspondingly. Values of the fixed parts of the complex refractive index were set as 0.05 for the imaginary part and 1.55 for the real part, for the cases with changing real and imaginary parts correspondingly. Specifically, Fig. 10 indicates that lidar ratio of the fine mode is less affected by the changes in refractive index compared to the coarse mode. This could be explained by smaller sensitivity of light scattering to the particle shape of the fine mode that is well illustrated in Fig. 10, showing stronger dependence of the lidar ratio on complex refractive index for the spherical particles of coarse mode. Therefore, since lidar measurements are sensitive mainly to the lidar ratio, lidar measurements do not provide significantly new information about the refractive index of fine mode.

Also, at shorter wavelengths the high molecular scattering reduces the aerosol contribution to the lidar signal. This also leads to a decrease of the sensitivity to the fine mode aerosol properties, as it was seen in Figs. 5-8, since a significant part of the information about fine fraction relies namely on shorter wavelengths.

It should be noted that a number of studies (Mishchenko et al., 2000, 2004; Dubovik et al., 2006) indicate high sensitivity of polarimetric passive measurements to the refractive index of the fine mode. Therefore, usage of radiometers with polarimetric capabilities could potentially result in better retrievals of the aerosol parameters of the fine mode.

\subsection{Improvements introduced by joint inversion of lidar and AERONET}

A synergetic handling of coincident radiometer and lidar data is obviously beneficial for the acquisition of improved vertical characterization of aerosol. The processing of lidar data always relies on assumptions about some aerosol properties. Obtaining this missing information from a nearby radiometer is evidently preferable to a simple assumption of these properties from climatologies. Therefore, the positive influence of the radiometer data on the lidar retrievals was emphasized in a number of previous studies (Chaikovsky et al., 2006c; Cuesta et al., 2008). However, all previous radiometer/lidar 

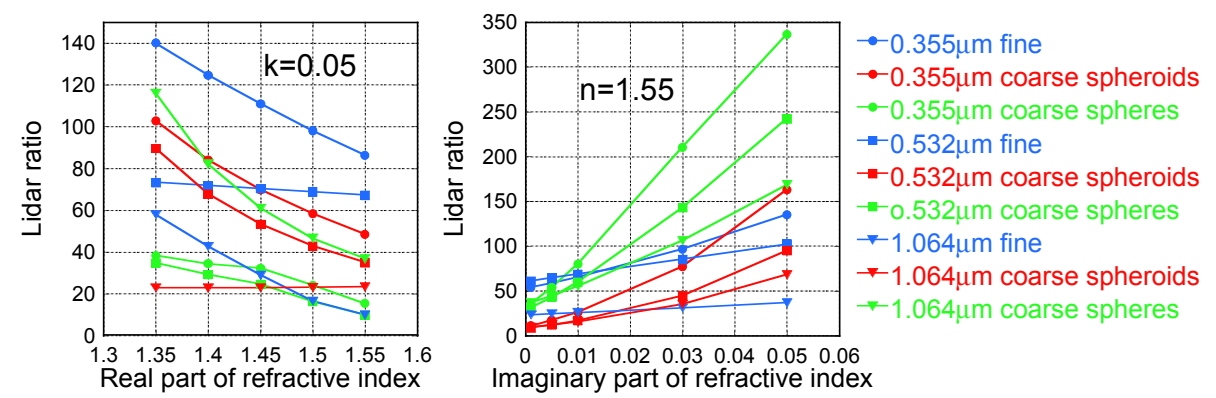

Fig. 10. Dependence of lidar ratio of fine and coarse modes on complex refractive index and particle shape.

synergy approaches used AERONET retrievals in the form of a priori assumptions for improving lidar retrievals. GARRLiC is the first development trying to explore the possibility of improving AERONET retrieval by using extra information of co-located lidar observations. The possibility to distinguish indices of the refraction of fine and coarse particles is one of the most significant innovations proposed by GARRLiC, since it was not achievable using only AERONET data as shown in studies by Dubovik et al. (2000). The results of sensitivity tests presented in a previous section showed the achievable levels of retrieval accuracy of the complex refractive index using both lidar and radiometer data. At the same time, it is clear that the lidar data provide additional information about aerosol properties because of high sensitivity of lidar data to aerosol lidar ratio. Therefore, in order to provide additional illustration of the positive effect from using lidar data on aerosol columnar properties, we analyse the changes in accuracy of the retrieval of lidar ratios by adding lidar data to AERONET observations. Also, any improvement in lidar ratio estimations brings straightforward enhancements in the retrieval of vertical profiles of aerosol concentrations.

With a purpose to access and illustrate the possible improvements in the retrieval of aerosol columnar properties, an additional scenario was added to the sensitivity study: inversion neglecting the measurements provided by lidar. Figure 11 shows the comparisons of errors of lidar ratio retrievals conducted for the AERONET data only and for a combination of AERONET and lidar. The lidar ratios were derived from size distributions that could be found in Fig. 4 for the "Urban" + "Dust" aerosol mixture with corresponding optical thickness of $0.8 / 0.2$ and $0.2 / 0.8$. The results demonstrate that joint retrieval allows more accurate retrievals of lidar ratio for both aerosol components in such challenging cases when one mode dominates in optical thickness. In such cases retrieval without lidar measurements tends to estimate all properties of both modes close to those of dominating one, leading to dramatic errors in lidar ratio estimations. The errors of the retrieval of the dominating mode lidar ratio remain almost the same for both inversion strategies. These results lead us to conclude that supplementing radiometer data by lidar observations helps to improve the retrieval of aerosol properties of minor mode in the aerosol
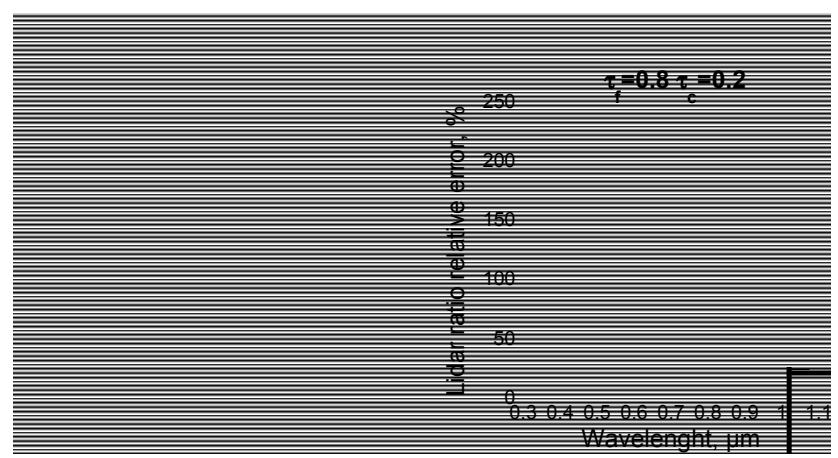

Fig. 11. Retrieval errors of lidar ratio with and without accountancy for lidar data.

mixture. Consequently, the retrieval of the vertical profile of the minor mode concentration also should be more accurate compared to the retrievals by the approaches of Chaikovsky et al. (2006c) and Cuesta et al. (2008) which assume lidar ratios from the AERONET retrievals.

Also, based on the observations made in Fig. 10, i.e. that lidar ratio is very sensitive to the retrieval accuracy of spherical particles faction, we have evaluated the possible improvements in the retrieval of this parameter by using joint inversion of AERONET and lidar data.

Table 3 summarizes the relative errors in retrieval of this parameter for three cases of aerosol with different partition of aerosol modes. The results were obtained for high aerosol load within three inversion scenarios: the joint inversion of radiometer and lidar data without any noise added; the joint inversion with random noise added to the data and the inversion of radiometer data only with random noise added to the observations. Although without information about polarization the sensitivity to this parameter is quite low and depends on aerosol optical thickness, the fact that backscatter depends on this parameter (see Fig. 10) allows decreasing retrieval errors in the situations when coarse mode dominates in optical thickness. As it is seen in Table 3, the absence of lidar data in the presence of the random noise makes accurate GARRLiC retrieval of this parameter impossible even in a situation with significant amount of coarse mode, while in the presence of 
Table 3. Relative errors of spherical particle faction retrieval.

\begin{tabular}{|c|c|c|c|c|c|}
\hline$\frac{\tau_{c}}{\tau_{f}}$ & $\tau_{f}$ & $\tau_{c}$ & $\begin{array}{c}\text { AERONET } \\
\quad+\text { lidar } \\
\text { no noise }\end{array}$ & $\begin{array}{l}\text { AERONET } \\
\text { noise added }\end{array}$ & $\begin{array}{l}\text { AERONET } \\
\quad+\text { lidar } \\
\text { noise added }\end{array}$ \\
\hline 0.25 & 0.8 & 0.2 & 0.99 & 1.00 & 0.98 \\
\hline 1 & 0.5 & 0.5 & 0.28 & 0.99 & 0.99 \\
\hline 4 & 0.2 & 0.8 & 0.02 & 0.89 & 0.03 \\
\hline
\end{tabular}

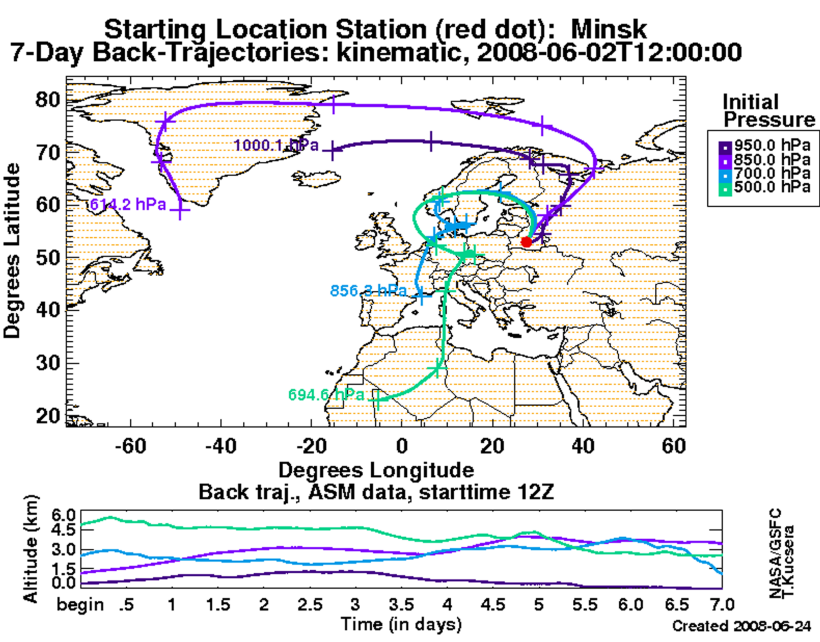

Fig. 12. Air mass back trajectories for the Minsk measurement site on 2 June 2008.

lidar data, sensitivity to this parameter remains for the same case of aerosol load.

The decrease of the retrieval error with growth of the coarse mode concentration is explained by higher sensitivity of the measurements to the shape parameters of bigger particles.

The analysis of test results allows us to conclude that, being supplied with sufficient measurement information, the combined inversion could provide deep synergy of two different types of aerosol remote sensing, resulting in more accurate and qualitative retrievals compared to the single instrument inversions.

\section{GARRLiC applications to real lidar/sun-photometer observations}

The algorithm has been applied to lidar/sun-photometer measurements collected at the observation site of the Laboratory of Scattering Media at the Institute of Physics, Minsk, Belarus. The station is equipped with the standard AERONET sun photometer and several multi-wavelength lidars that provided measurements of attenuated backscatter at 0.355 , 0.532 and $1.064 \mu \mathrm{m}$.

Parameters that characterize noise (Eq. 20) in these lidar systems were estimated as shown in Table 4.

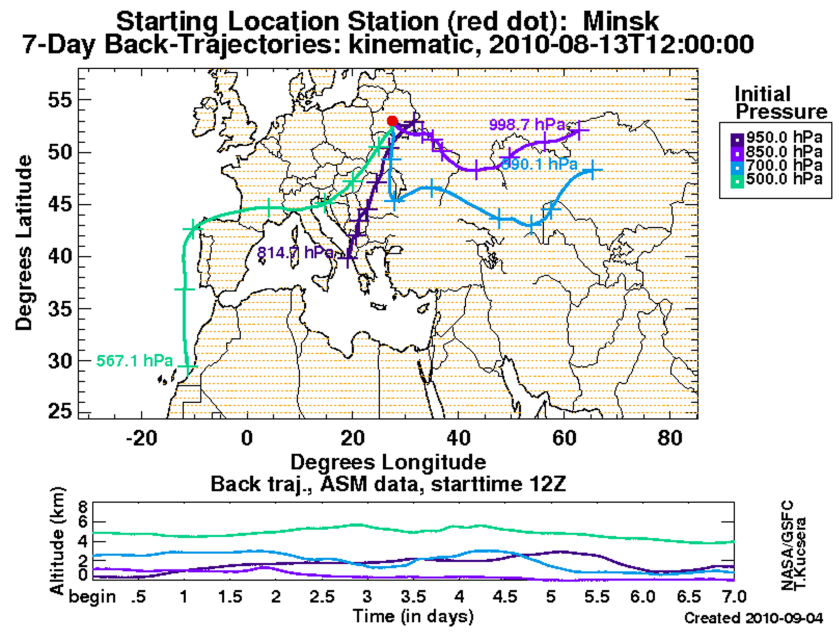

Fig. 13. Air mass back trajectories for the Minsk measurement site on 13 August 2010.
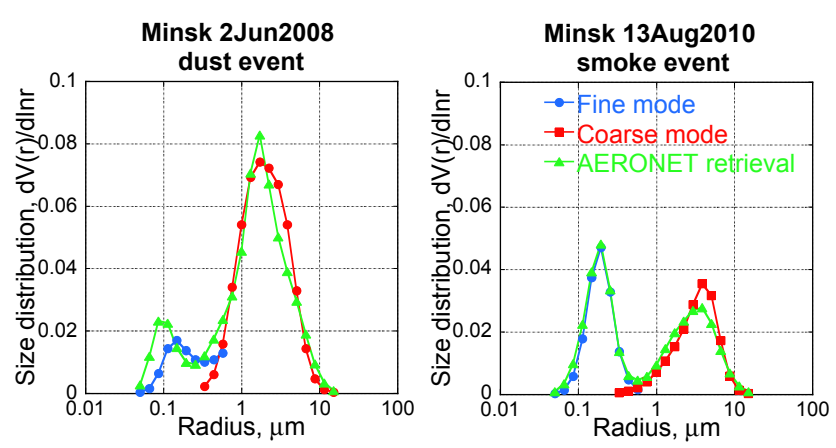

Fig. 14. Retrieved aerosol size distributions.

Two typical situations were chosen to illustrate the inversion results: (i) the observation of dust outburst from the Sahara transported over Minsk on 2 June 2008 and (ii) observation on 13 August 2010 of smoke plum transported from Russian forest fires over eastern Europe. The total optical thicknesses for these cases were $\tau_{440}=0.36$ and $\tau_{440}=0.46$ correspondingly. Figures 12 and 13 show the atmosphere back trajectories provided for Minsk AERONET site (http: //croc.gsfc.nasa.gov/aeronet/, Schoeberl and Newman, 1995; Pickering et al., 2001) for these cases. The analysis of these back trajectories illustrates that air masses from mentioned regions should be present over Minsk during measurement periods.

Figures 14 and 15 present the retrieved aerosol columnar microphysical properties and Figs. 17 and 18 show the retrieved columnar optical parameters all in comparison with standard AERONET retrievals for this site. Figures 16 and 19-21 present the retrieved vertical profiles of microphysical and optical aerosol properties. Figure 22 is dedicated to qualifications of the vertical retrievals, presenting 
Table 4. Parameters of noise estimations for the lidar system.

\begin{tabular}{lcccccc}
\hline Parameter & $v$ & $g$ & $q$ & $u$ & $\alpha_{1}$ & $\alpha_{2}$ \\
\hline Value & $10^{-5}$ & $10^{-4}$ & $10^{-1}$ & 1 & $10^{-1}$ & $10^{-3}$ \\
\hline
\end{tabular}
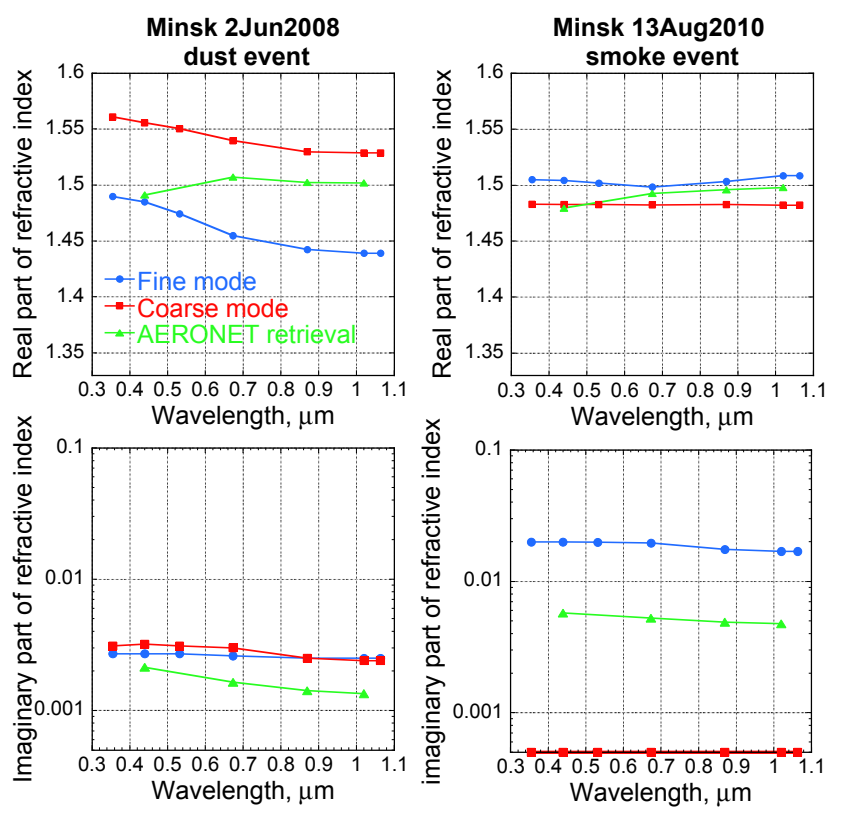

Fig. 15. Retrieved aerosol complex refractive indices.

the comparison of GARRLiC results with LiRIC retrievals made for the same measurements.

The retrieved size distributions (Fig. 14) are consistent with the expectations for observed aerosol types: domination of fine mode for smoke and of coarse mode for desert dust. Both retrievals show good agreement with AERONET retrievals. The difference in the fine mode retrievals between the two methods in the dust observation case could probably be explained by lower sensitivity of the AERONET inversion to minor aerosol modes. Observed size shift in the favour of larger particles for both cases could be explained by influence of the lidar data on the retrieval.

The retrieved refractive indices (Fig. 15) are clearly distinguished between modes and are coherent with the values expected for these aerosol types: highly absorbing fine mode for smoke, and the real part of the refractive index for coarse mode close to the observations of this parameter for dust (Dubovik et al., 2002a). Since, the AERONET retrieval does not discriminate the refractive index of the modes, the AERONET derived values cannot be compared directly to the GARRLiC retrieval. Nonetheless, it is clear that there is logical agreement between two retrievals since the AERONET derived refractive indices are generally in the middle between values of fine and coarse modes obtained by GARRLiC. Two trends observed in the retrievals of the imaginary part of refractive indexes should be outlined: high
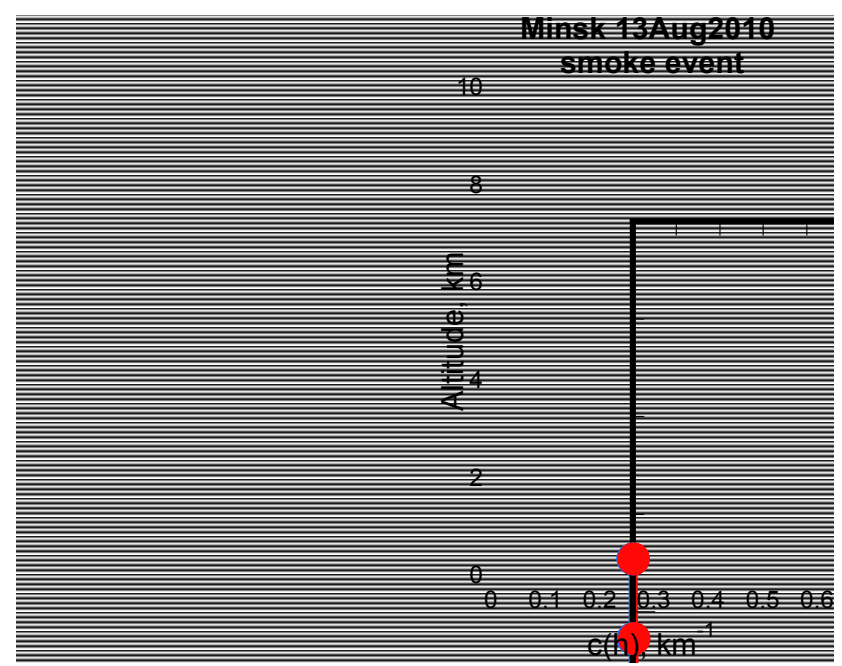

Fig. 16. Retrieved vertical concentration profiles.

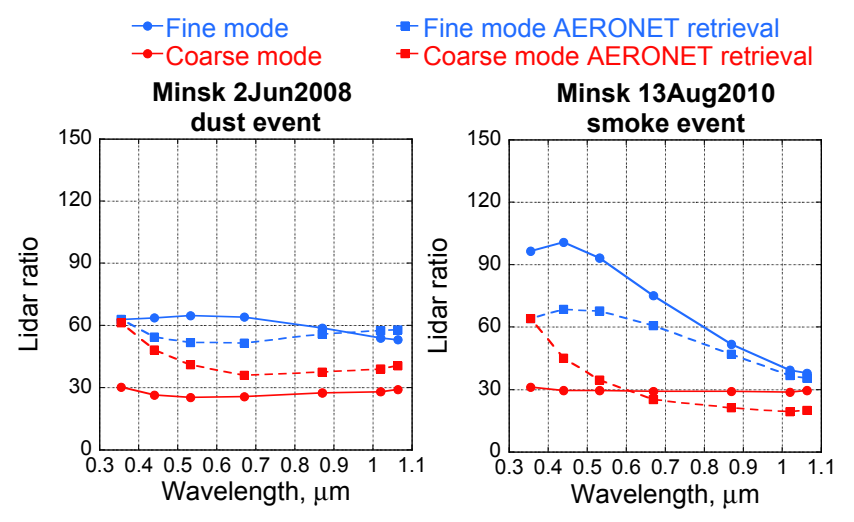

Fig. 17. Retrieved aerosol lidar ratios.

absorption of the fine particles in the dust case and very low absorption of the coarse particles for the smoke case (see bottom panels in Fig. 15). Such retrievals could be explained by very low optical thickness of the minor modes $\left(\tau_{f}=0.19\right.$ for the dust case and $\tau_{c}=0.04$ for the smoke case). As it was demonstrated by the sensitivity study, such low contributions of the minor modes could lead to high estimation errors in their complex refractive index.

The vertical distributions of fine and coarse modes (Fig. 16) clearly discriminate the vertical structure of the aerosols of different types. Both retrievals agree well with back-trajectory analysis: according to Figs. 12 and 13, the atmospheric layer from the region of forest fires was expected at the altitude of about $2 \mathrm{~km}$, and the layer from the Sahara was expected at around $4 \mathrm{~km}$.

Retrievals of lidar ratios shown in Fig. 17 demonstrate notable differences between the AERONET and GARRLiC values. The main difference is located at shorter wavelengths. These differences are probably caused by the significant differences in the sensitivities of both data sets, and by the 

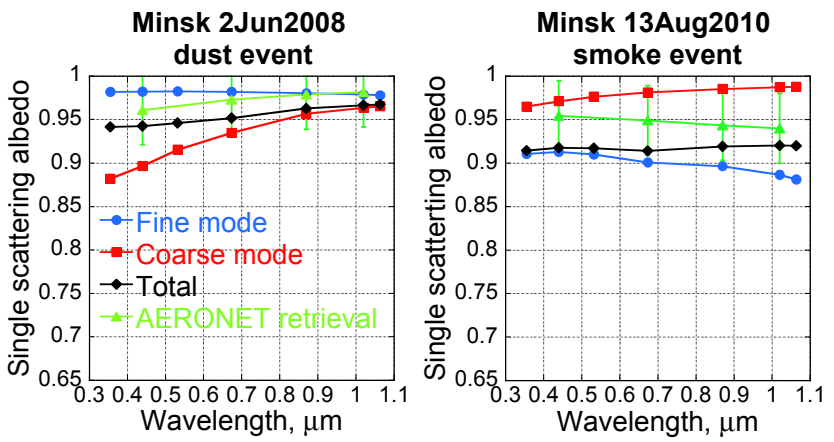

Fig. 18. Retrieved aerosol single-scattering albedo.

differences in assumptions. Specifically, the AERONET radiometer does not include observations in backscattering direction, and assumption of size independent refractive index may also result in an additional error in the lidar ratio estimation.

The spherical particles faction retrieved for these two cases gave $40 \%$ of spherical particles for the smoke event and $25 \%$ for the dust event, compared to the 99 and $2 \%$ from the AERONET retrievals. This difference can be explained by high sensitivity of the lidar measurements to backscatter from non-spherical particles (see Dubovik et al., 2006 and Fig. 10).

Figure 18 illustrates the retrievals of columnar singlescattering albedo (SSA). The total (i.e. mixture of fine and coarse) SSA shows good agreement with AERONET retrievals, climatological (Dubovik et al., 2002a) and observed (Toledano et al., 2011) values. Both spectral dependencies of smoke and dust single-scattering albedos were retrieved. The total single-scattering albedo is closer to the value of the dominating aerosol mode for both retrievals. This also could be explained by low contributions of the minor modes to the total optical thickness and higher absorption estimations of the dominating aerosol components.

Figures 19-21 demonstrate the vertical distributions of single-scattering albedos, lidar ratios and extinction calculated using retrieved parameters at the wavelengths of lidar measurements. All distributions have a noticeable vertical structure that agrees with the retrieved vertical distributions of aerosol concentrations. The values of singlescattering albedo (see Fig. 19) at all single layers are in the ranges of typical values for dust and smoke aerosols (e.g. Toledano et al., 2011). The retrieved lidar ratios (Fig. 20) are in the ranges of values for dust and smoke aerosols given by Dubovik et al. (2002a) and Cattrall et al. (2005). These values, however, are lower than the assumptions for dust particles given by Schuster et al. (2012), Groß et al. (2011) or by Tesche et al. $(2009,2011)$. The lower lidar ratios in this case could have been caused by contamination of the pure dust layers during the long-range aerosol transport depicted in Fig. 12. Strong spectral dependence of the smoke lidar
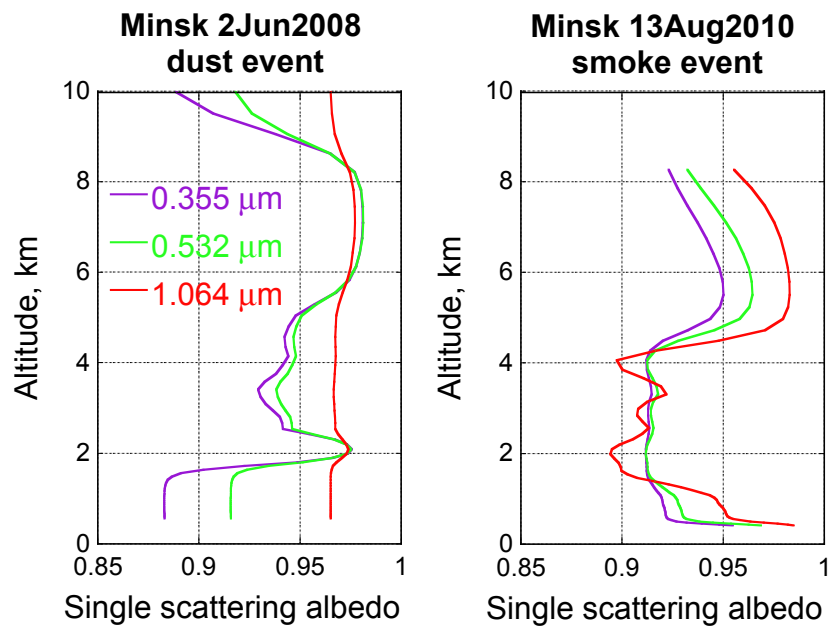

Fig. 19. Retrieved vertical profiles of aerosol single-scattering albedo.
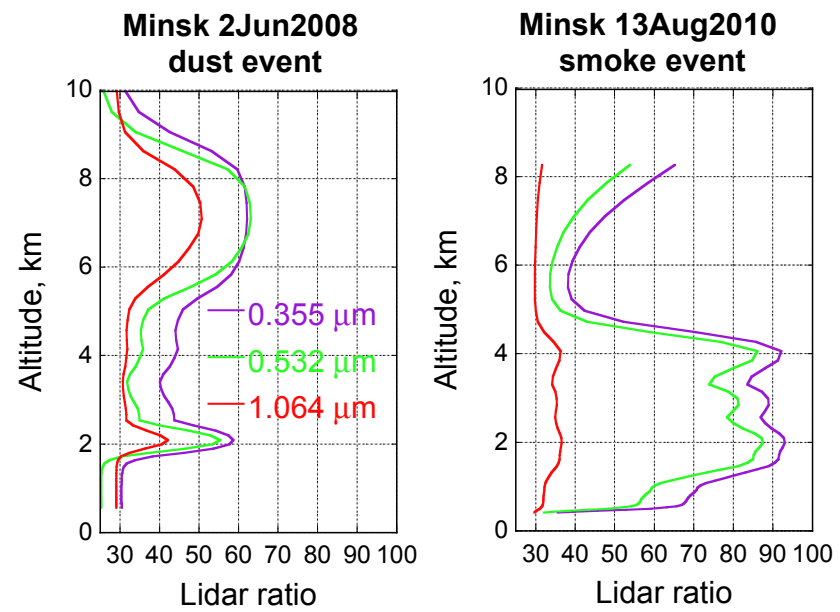

Fig. 20. Retrieved vertical profiles of aerosol lidar ratio.

ratio observed in Fig. 20 illustrates the fact that IR (infrared) light has less pronounced scattering on the smoke particles than light at the shorter wavelengths.

It should be noted, that the particular behaviour of profiles in Figs. 19 and 20 at higher altitudes could be explained by a very small amount of the aerosol present in the upper atmosphere layers and very weak signal returned from this altitude range.

Figure 22 is aimed to demonstrate the consistency between the LiRIC and GARRLiC retrievals in a case where no differences are expected. Both algorithms provide two distinct vertical concentration profiles for different aerosol components and the comparison of profiles retrieved by GARRLiC and LiRIC was made. The main difference is that GARRLiC modifies the retrieved columnar properties of aerosol. In addition, GARRLiC uses a bi-component aerosol model that may have different complex refractive indexes. This assumption affects estimations of lidar ratios for each mode and 

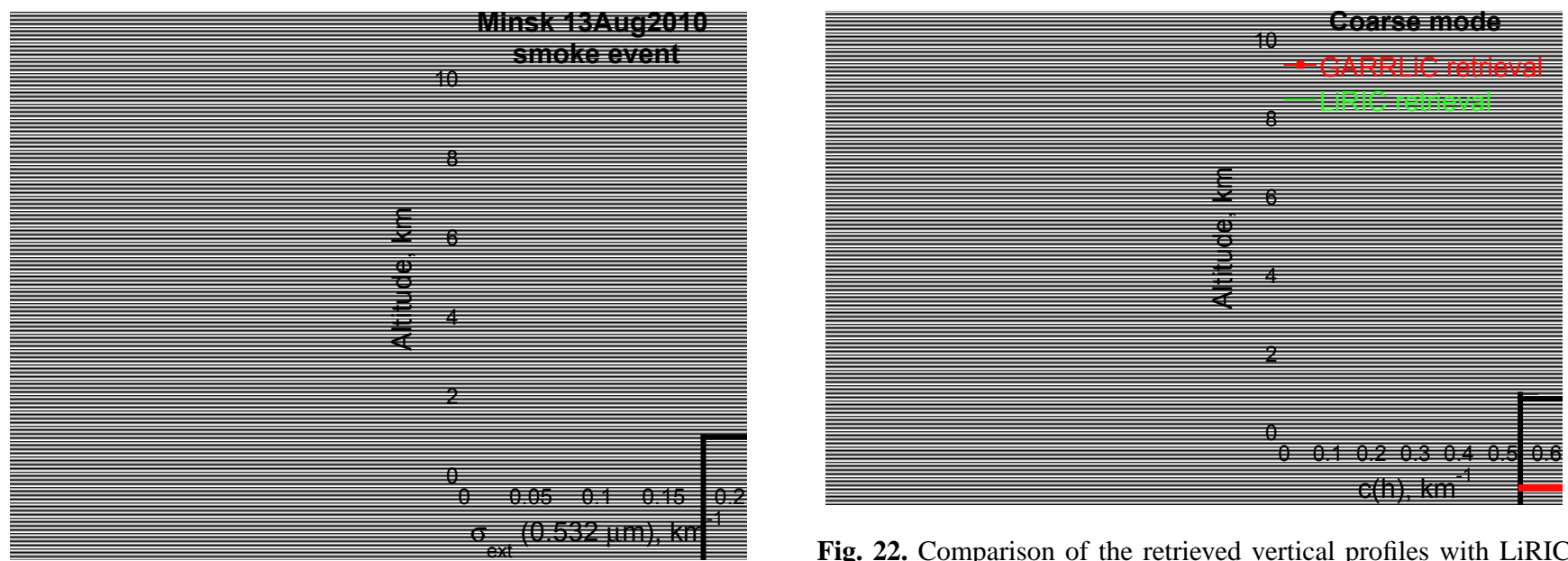

Fig. 21. Retrieved vertical profiles of aerosol extinction.

therefore affects the retrieved vertical profiles. Therefore, the demonstration of LiRIC and GARRLiC codes consistency has been performed using the case with small difference in complex refractive indices of fine and coarse aerosol modes (see Fig. 15).

Figure 22 shows vertical distributions retrieved by GARRLiC compared with the results of the LiRIC inversion (Chaikovsky et al., 2012) made for the same measurement set during a smoke event. Both retrieved profiles are in good agreement. The minor differences could be explained by the smaller amount of altitude layers in the GARRLiC retrieval and differences in lidar ratio estimations for both modes. Therefore, in situations when the usage of the same values of complex refractive indices for both aerosol modes could be justified, these two methods should provide similar results, demonstrating the succession of the newer method. We have observed that in less favourable situations the AERONET estimates of the lidar ratio for aerosol components can show more significant deviations compared with the ones retrieved by GARRLiC, thus affecting the retrievals of vertical concentration profiles more drastically.

Thus, the results of GARRLiC application to the real data and their comparisons to the AERONET and LiRIC retrieval results showed an encouraging agreement for both columnar and vertical properties of aerosol. At the same time, the GARRLiC retrieval differentiates between columnar optical properties of fine and coarse modes of aerosol relying on additional information contained in lidar observations.

\section{Conclusions}

This paper has discussed in detail a concept for a new GARRLiC algorithm developed for deriving detailed properties of two atmospheric aerosol components from coincident lidar and photometric measurements. The algorithm is developed using the heritage of the AERONET, PARASOL and LiRIC

Fig. 22. Comparison of the retrieved vertical profiles with LiRIC inversion for observations on 13 August 2010.

algorithms. The algorithm is designed to invert the coincident observations of the CIMEL sun/sky photometer that registers direct and scattered atmospheric radiation at four wavelengths in up to 35 directions and multi-wavelength elastic lidar that registers backscattered radiation at three wavelengths in up to 1000 altitude layers. The algorithm derives an extended set of parameters for both columnar and vertical aerosol properties, including aerosol sizes, shape, spectral complex refractive index for both fine and coarse aerosol modes, as well as vertical profiles of mode concentrations.

The concept of the algorithm is aimed to achieve a higher accuracy in the retrieval, since in such an approach the solution usually relying only on passive measurement of the radiometer is benefiting from information contained in coincident active observations by lidar, and this method uses a smaller number of assumptions about aerosol. This paper provides a detailed description of the full set of formulations necessary for realizing this concept.

The performance of the developed algorithm has been demonstrated by application to both synthetically generated and real coincident sun-photometer and lidar observations. First, a series of sensitivity tests were conducted by applying the algorithm to the synthetic sun-photometer and lidar observations for the cases of aerosol mixtures containing desert dust with urban pollution and biomass burning aerosols. The simulations were designed to mimic the observations of real aerosol. With this purpose, aerosol models derived from the AERONET observations at Solar Village (Saudi Arabia), African savanna (Zambia) and the GSFC (Greenbelt, MD) were used to generate synthetic proxy measurements, both photometric and both photometric and lidar. The data were perturbed by random noise before applying the retrieval algorithm. The results of the tests showed that the complete set of aerosol parameters for each aerosol component can be robustly derived with acceptable accuracy in all considered situations. Lower estimation errors for lidar ratios of the aerosol components compared to the AERONET 
retrievals were achieved. The better accuracy was observed for the higher aerosol load.

In addition, the GARRLiC algorithm was applied to coincident lidar and sun-photometer observations performed at Minsk (Belarus) AERONET site. The comparison of the derived aerosol properties with available observations by AERONET ground-based sun/sky-radiometers indicated encouraging consistency of microphysical parameters of aerosol components derived from joint inversion with those obtained by the AERONET retrieval. More comprehensive studies for testing and tuning the developed algorithm including accountancy for polarization effects both for sunphotometer and lidar observations are planned in future efforts. Such important aspects of algorithm implementation as coincident measurements requirements are to be addressed in follow-up studies.

The described GARRLiC algorithm is not only limited to ground observations or to the used instrument types. The presented concept could be adapted to a variety of aerosol remote sensing instruments available, including ground-based polarimetric measurements of both sun photometers and lidars, Raman scattering lidars and spaceborne systems like PARASOL and CALIPSO, providing wider opportunities in global comprehensive aerosol characterization.

Acknowledgements. The authors are very thankful to AERONET for establishing and maintaining the sites used in this work. This research has been supported by the University of Lille, and Region Nord-Pas-de-Calais. A. Lopatin was supported by a CROUS/CNOUS fellowship of the French Government. The research leading to these results has received funding from the European Union Seventh Framework Program (FP7/2007-2013) under grant agreement No. 262254. The publication of this article is financed by CNRS-INSU.

Edited by: T. Wagner

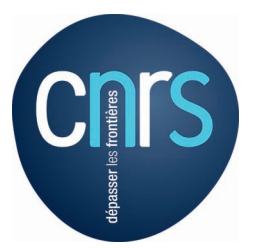

The publication of this article is financed by CNRS-INSU.

\section{References}

Adam, M., Pahlow, M., Kovalev, V. A., Ondov, J. M., Parlange, M. B., and Nair, N.: Aerosol optical characterization by nephelometer and lidar: The Baltimore Supersite experiment during the Canadian forest fire smoke intrusion, J. Geophys. Res., 109, D16S02, doi:10.1029/2003JD004047, 2004.

Ahmad, Z., Franz, B. A., McClain, C. R., Kwiatkowska, E. J., Werdell, J., Shettle, E. P., and Holben, B. N.: New aerosol models for the retrieval of aerosol optical thickness and normalized water-leaving radiances from the SeaWiFS and MODIS sensors over coastal regions and open oceans, Appl. Optics, 49, 55455560, 2010.

Althausen, D., Engelmann, R., Baars, H., Heese, B., Ansmann, A., and Müller, D.: Portable Raman Lidar PollyXT for Automated Profiling of Aerosol Backscatter, Extinction, and Depolarization, J. Atmos. Ocean. Tech., 26, 2366-2378, 2009.

Ansmann, A., Riebersell, M., Wandinger, U., Weitkamp, C., Voss, E., Lahmann, W., and Michaelis, W.: Combined raman-elastic lidar for vertical profiling of moisture, aerosols extinction, backscatter and lidar ratio, Appl. Phys., 55, 18-28, 1992.

Ansmann, A., Tesche, M., Groß, S., Freudenthaler, V., Seifert, P., Hiebsch, A., Schmidt, J., Wandinger, U., Mattis, I., Müller, D., and Wiegner, M.: The 16 April 2010 major volcanic ash plume over central Europe: EARLINET lidar and AERONET photometer observations at Leipzig and Munich, Germany, Geophys. Res. Lett., 37, L13810, doi:10.1029/2010GL043809, 2010.

Ansmann, A., Petzold, A., Kandler, K., Tegen, I., Wendisch, M., Müller, D., Weinzierl, B., Müller, T., and Heintzenberg, J.: Saharan Mineral Dust Experiments SAMUM-1 and SAMUM-2: what have we learned?, Tellus B, 63, 403-429, doi:10.1111/j.16000889.2011.00555.x, 2011a.

Ansmann, A., Tesche, M., Seifert, P., Groß, S., Freudenthaler, V., Apituley, A., Wilson, K. M., Serikov, I., Linné, H., Heinold, B., Hiebsch, A., Schnell, F., Schmidt, J., Mattis, I., Wandinger, U., and Wiegner, M.: Ash and fine mode particle mass profiles from EARLINET/AERONET observations over central Europe after the eruptions of the Eyjafjallajökull volcano in 2010, J. Geophys. Res., 116, D16S02, doi:10.1029/2003JD004047, 2011b.

Antuña, J., Andrade, M., Landulfo, E., Clemesha, B., Quel, E., and Bastidas, A., Clemesha, B., Quel, E., and Bastidas, A.: Building a Lidar Network in Latin America: Progress and Difficulties, in: 23rd International Laser Radar Conference, 24-28 July 2006, Nara, Japan, 2006.

Baars, H., Althausen, D., Engelmann, R., Ansmann, A., Müller, D. Artaxo, P., Pauliquevis, T., Souza, R., and Martin, S. T.: Automated Raman lidar measurements in the Amazon rain forest during the wet and dry season 2008, in: Proceedings of the 8th International Symposium on Tropospheric Profiling, 19-23 October 2009, vol. S04, edited by: Apituley, A., Russchenberg, H., and Monna, W., Delft, the Netherlands, 1-4, 2009.

Barker, J. and Tingey, D. T.: Air Pollution Effects on Biodiversity, Springer, New York, 1992.

Bösenberg, J.: EARLINET-A European Aerosol Research Lidar Network, Advances in Laser Remote sensing, in: Selected papers 20th Int. Laser Radar Conference (ILRC), 10-14 July 2000, Vichi, France, 155-158, 2000.

Bösenberg, J. and Hoff, R. M.: Plan for the implementation of the GAW Aerosol Lidar Observation Network GALION, WMO/TDNo. 1443 178, GAW, Hamburg, Germany, 2007. 
Bréon, F.-M.: How Do Aerosols Affects Cloudiness and Climate?, Science, 313, 623-624, doi:10.1126/science.1131668, 2006.

Bréon, F. M., Buriez, J. C., Couvert, P., Deschamps, P. Y., Deuzé, J. L., Herman, M., Goloub, P., Leroy, M., Lifermann, A., Moulin, C., Parol, F., Seze, G., Tanré, D., Vanbauce, C., and Vesperini, M.: Scientific results from the POLarization and Directionality of the Earth's Reflectances (POLDER), Adv. Space Res., 30, 23832386, 2002.

Burton, S. P., Ferrare, R. A., Hostetler, C. A., Hair, J. W., Rogers, R. R., Obland, M. D., Butler, C. F., Cook, A. L., Harper, D. B., and Froyd, K. D.: Aerosol classification using airborne High Spectral Resolution Lidar measurements - methodology and examples, Atmos. Meas. Tech., 5, 73-98, doi:10.5194/amt-5-73-2012, 2012.

Cattrall, C., Reagan, J., Thome, K., and Dubovik, O.: Variability of aerosol and spectral lidar and backscatter and extinction ratios of key aerosol types derived from selected Aerosol Robotic network locations, J. Geophys. Res., 110, D10S11, doi:10.1029/2004JD005124, 2005.

Chaikovsky, A., Dubovik, O., Holben, B. N., and Bril, A. I.: Methodology to retrieve atmospheric aerosol parameters by combining ground-based measurements of multiwavelength lidar and sun sky-scanning radiometer, in: Proceeding of Eight International Symposium on Atmospheric and Ocean and Ocean Optics: Atmospheric Physics, edited by: Zherebtsov, G. A., Matvienko, G. G., Banakh, V. A., and Koshelev, V. V., Proc. SPIE, 4678, 257-268, doi:10.1117/12.458450, 2002.

Chaikovsky, A., Bril, A., Dubovik, O., Holben, B., Thompson, A., Goloub, P., O’Neill, N., Sobolewski, P., Bösenberg, J., Ansmann, A., Wandinger, U., and Mattis, I.: CIMEL and multiwavelength lidar measurements for troposphere aerosol altitude distributions investigation, long-range transfer monitoring and regional ecological problems solution: field validation of retrieval techniques, Óptica Pura y Aplicada, 37, 3241-3246, 2004.

Chaikovsky, A., Bril, A., Denisov, S., and Balashevich, N.: Algorithms and software for lidar data processing in CIS-LiNet, in: Reviewed and Revised Papers Presented at the 23rd International Laser radar Conference, 24-28 July 2006, edited by: Chikao Nagasava, N. S., Nara, Japan, 667-670, 2006a.

Chaikovsky, A., Ivanov, A., Balin, Y., Elnikov, A., Tulinov, G., Plusnin, I., Bukin, O., and Chen, B.: Lidar network CIS- LiNet for monitoring aerosol and ozone in CIS regions, in: Proc. Twelfth Joint International Symposium on Atmospheric and Ocean Optics/Atmospheric Physics, edited by: Zherebtsov, G. G. M., Proc. SPIE, 6160, 616035-616039, doi:10.1117/12.675920, 2006b.

Chaikovsky, A., Ivanov, A., Korol, M., Slesar, A. S. D., Osipenko, F., Hutko, I., Dubovik, O., Holben, B., and Goloub, P.: Atmospheric participate matter variability in an industrial center from multi-wavelength lidar and Sun-sky radiometer measurements, in: Proc. Twelfth Joint International Symposium on Atmospheric and Ocean Optics/Atmospheric Physics, edited by: Zherebtsov, G. G. M., Proc. SPIE, 6160, 61601Y-61601Y-12, doi:10.1117/12.675466, 2006c.

Chaikovsky, A., Dubovik, O., Goloub, P., Tanré, D., Chaikovskaya, L., Denisov, S., Grudo, Y., Lopatsin, A., Karol, Y., Lapyonok, T., Korol, M., Osipenko, F., Savitski, D., and Slesar, A.: Combined lidar and radiometric sounding of atmospheric aerosol: algorithm of data processing, software, dessimination, in: Proceedings of XVIII International symposium "Atmospheric and ocean optics.
Atmosphere physics”, 2-6 July 2012, Irkutsk, Russian Federation, C1-C4, 2012.

Charlson, R. J., Schwartz, S. E., Hales, J. M., Cess, R. D., Coakley, J. A., Hansen, J. E., and Hofmann, D. J.: Aerosols and global warming response, Science, 256, 598-599, 1992.

Costa, M., Levizzani, V., and Silva, A. M.: Part II: Aerosol characterization and direct radiative forcing assessment over the ocean: Application to test cases and validation, J. Appl. Meteorol., 43, 1818-1833, 2004

Cuesta, J., Flamant, H. P., and Flamant, C.: Synergetic technique combining elastic backscatter lidar data and sunphotometer AERONET inversion for retrieval by layer of aerosol optical and microphysical properties, Appl. Optics, 47, 4598-4611, 2008.

D’Almeida, G. A., Koepke, P., and Shettle, E. P.: Atmospheric Aerosols: Global Climatology and Radiative Characteristics, A. Deepak Pub., p. 561, 1991.

Denisov, S., Chaikovsky, A., Bril, A., and Balashevich, N.: Integrated software for lidar data processing, in: Proceedings Of International Workshop ISTC "Baikal 2006", Monitoring of largescale atmosphere changes in CIS regions: co-operation of the international measuring networks AERONET, EARLINET, ADNet, NDSC, as well as scientific groups in CIS, 15-19 August 2006, Irkutsk, Russia, 41-43, 2006.

Di Girolamo, P., Summa, D., Bhawar, R., Di Lorio, T., Cacciani, M., Veselovskii, I., Dubovik, O., and Kolgotin, A.: Raman lidar observations of a Saharan dust outbreak event: Characterization of the dust optical properties and determination of particle size and microphysical parameters, J. Atmos. Environ., 50, 66-78, doi:10.1016/j.atmosenv.2011.12.061, 2012.

Dubovik, O.: Optimization of Numerical Inversion in Photopolarimetric Remote Sensing, in: Photopolarimetry in Remote Sensing, edited by: Videen, G., Yatskiv, Y., and Mishchenko, M., Kluwer Academic Publishers, Dordrecht, the Netherlands, 65106, 2004.

Dubovik, O. and King, M.: A flexible inversion algorithm for retrieval of aerosol optical properties from Sun and sky radiance measurements, J. Geophys. Res., 105, 20673-20696, doi:10.1029/2000JD900282, 2000.

Dubovik, O., Lapyonok, T., and Oshchepkov, S.: Improved technique for data inversion: optical sizing of multicomponent aerosols, Appl. Optics, 34, 8422-8436, 1995.

Dubovik, O., Yokota, T., and Sasano, Y.: Improved technique for data inversion and its application to the retrieval algorithm for adeos/ilas, Adv. Space Res., 21, 397-403, 1998.

Dubovik, O., Smirnov, A., Holben, B. N., King, M., Kaufman, Y. J., Eck, T. F., and Slutsker, I.: Accuracy assessments of aerosol optical properties retrieved from Aerosol Robotic Network (AERONET) sun and sky radiance measurements, J. Geophys. Res., 105, 9791-9806, 2000.

Dubovik, O., Holben, B., Eck, T., Smirnov, A., Kaufman, Y., King, M., Tanré, D., and Slutsker, I.: Variability of absorption and optical properties of key aerosol types observed in worldwide locations, J. Atmos. Sci., 59, 590-608, 2002a.

Dubovik, O., Holben, B. N., Lapyonok, T., Sinyuk, A., Mishchenko, M. I., Yang, P., and Slutsker, I.: Non-spherical aerosol retrieval method employing light scattering by spheroids, Geophys. Res. Lett., 29, 54-1-54-4, doi:10.1029/2001GL014506, 2002 b. 
Dubovik, O., Sinyuk, A., Lapyonok, T., Holben, B. N., Mishchenko, M., Yang, P., Eck, T. F., Volten, H., Munoz, O., Veihelmann, B., van der Zande, W. J., Leon, J.-F., Sorokin, M., and Slutsker, I.: Application of spheroid models to account for aerosol particle nonsphericity in remote sensing of desert dust, J. Geophys. Res., 111, D11208, doi:10.1029/2005JD006619, 2006.

Dubovik, O., Herman, M., Holdak, A., Lapyonok, T., Tanré, D., Deuzé, J. L., Ducos, F., Sinyuk, A., and Lopatin, A.: Statistically optimized inversion algorithm for enhanced retrieval of aerosol properties from spectral multi-angle olarimetric satellite observations, Atmos. Meas. Tech., 4, 975-1018, doi:10.5194/amt-4975-2011, 2011.

Eck, T. F., Holben, B. N., Dubovik, O., Smirnov, A., Goloub, P., Chen, H. B., Chatenet, B., Gomes, L., Zhang, X.-Y., Tsay, S.C., Ji, Q., Giles, D., and Slutsker, I.: Columnar aerosol optical properties at AERONET sites in Central-eastern Asia and aerosol transport to the tropical mid Pacific, J. Geophys. Res., 110, 9751018, doi:10.1029/2004JD005274, 2005.

Eck, T. F., Holben, B. N., Reid, J. S., Giles, D. M., Rivas, M. A., Singh, R. P., Tripathi, S. N., Bruegge, C. J., Platnick, S., Arnold, G. T., Krotkov, N. A., Carn, S. A., Sinyuk, A., Dubovik, O., Arola, A., Schafer, J. S., Artaxo, P., Smirnov, A., Chen, H., and Goloub, P.: Fog- and cloud-induced aerosol modification observed by the Aerosol Robotic Network (AERONET), J. Geophys. Res., 117, D07206, doi:10.1029/2011JD016839, 2012.

Fernald, F. G.: Analysis of atmospheric lidar observations - Some comments, Appl. Optics, 23, 652-653, 1984.

Fernald, F. G., Herman, B. M., and Reagan, J. A.: Determination of aerosol height distributions by lidar, J. Appl. Meteorol., 11, 482-489, 1972.

Ferrare, R. A., Melfi, S. H., Whiteman, D. N., Evans, K. D., Leifer, R., and Kaufman, Y. J.: Raman lidar measurements of aerosol extinction and backscattering 1. Methods and comparisons, J. Geophys. Res., 103, 19663-19672, 1998a.

Ferrare, R. A., Melfi, S. H., Whiteman, D. N., Evans, K. D., Poellot, M., and Kaufman, Y. J.: Raman lidar measurements of aerosol extinction and back-scattering 2. Derivation of aerosol real refractive index, single-scattering albedo, and humidification factor using Raman lidar and aircraft size distribution measurements, J. Geophys. Res., 103, 19673-19690, 1998 b.

Fleming, E., Chandra, S., Shoeberl, M., and Barnett, J.: Mean Global Climatology of Temperature, Wind, Geopotential Height, and Pressure for $0-120 \mathrm{~km}$, NASA Technical Memorandum 100697, NASA, Washington, D.C., 1988.

Forster, P., Ramaswany, V., Artaxo, P., Bernsten, T., Betts, R., Fahey, D. W., Haywood, J., Lean, J., Lowe, D., Myhre, G., Nganga, J., Prinn, R., Raga, G., Schulz, M., and Dorland, R. V.: Changes in atmospheric constituents and in radiative forcing, Climate change 2007: the physical science basis. Contribution of working group I to the fourth assessment report of Intergovernmental Panel on Climate change, IPCC report, IPCC, Cambridge University Press, Cambridge, UK and New York, NY, USA, 2007.

Gatebe, C. K., Dubovik, O., King, M. D., and Sinyuk, A.: Simultaneous retrieval of aerosol and surface optical properties from combined airborne- and ground-based direct and diffuse radiometric measurements, Atmos. Chem. Phys., 10, 2777-2794, doi:10.5194/acp-10-2777-2010, 2010.
Gobbi, G. P., Barnaba, F., Van Dingenen, R., Putaud, J. P., Mircea, M., and Facchini, M. C.: Lidar and in situ observations of continental and Saharan aerosol: closure analysis of particles optical and physical properties, Atmos. Chem. Phys., 3, 2161-2172, doi:10.5194/acp-3-2161-2003, 2003.

Groß, S., Tesche, M., Freudenthaler, V., Toledano, C., Wiegner, M., Ansmann, A., Althausen, D., and Seefeldner, M.: Characterization of Saharan dust, marine aerosols and mixtures of biomassburning aerosols and dust by means of multi-wavelength depolarization and Raman lidar measurements during SAMUM 2, Tellus B, 63, 706-724, doi:10.1111/j.1600-0889.2011.00556.x, 2011.

Groß, S., Esselborn, M., Abicht, F., Wirth, M., Fix, A., and Minikin, A.: Airborne high spectral resolution lidar observation of pollution aerosol during EUCAARI-LONGREX, Atmos. Chem. Phys., 13, 2435-2444, doi:10.5194/acp-13-2435-2013, 2013.

Hair, J., Hostetler, C., Cook, A., Harper, D., Ferrare, R., Mack, T., Welch, W., Izquierdo, L., and Hovis, F. E.: Airborne High Spectral Resolution Lidar for Profiling Aerosol Optical Properties, Appl. Optics, 47, 6734-6752, doi:10.1364/AO.47.006734, 2008.

Hansen, J., Sato, M., Kharecha, P., and von Schuckmann, K.: Earth's energy imbalance and implications, Atmos. Chem. Phys., 11, 13421-13449, doi:10.5194/acp-11-13421-2011, 2011.

Harrison, R. M. and Yin, J.: Particulate matter in the atmosphere: Which particle properties are important for its effects on health, Sci. Total Environ., 249, 85-101, 2000.

Hasekamp, O. P., Litvinov, P., and Butz, A.: Aerosol properties over the ocean from PARASOL multiangle photopolarimetric measurements, J. Geophys. Res.-Atmos., 116, D14204, doi:10.1029/2010JD015469, 2011.

Hobbs, P. V.: Aerosol-cloud interactions, in Aerosol-Cloud-Climate Interactions, Academic, San Diego, California, 33-69, 1993.

Hoff, R. M., Wiebe, H. A., and Guise-Bagley, L.: Lidar, nephelometer, and in situ aerosol experiments in southern Ontario, J. Geophys. Res., 101, 19199-19209, 1996.

Holben, B.: AERONET-A federated instrument network and data archive for aerosol characterization, Remote Sens. Environ., 66, 1-16, 1998.

Holben, B., Eck, T., Schafer, J., Giles, D., and Sorokin, M.: Distributed Regional Aerosol Gridded Observation Networks (DRAGON), White Paper, http://aeronet.gsfc.nasa.gov/ new_web/Documents/DRAGON_White_Paper_A_system_of_ experiment.pdf (last access: August 2013), 2011.

Huebert, B. J., Bates, T., Russell, P. B., Shi, G., Kim, Y. J., Kawamura, K., Carmichael, G., and Nakajima, T.: An overview of ACE-Asia: Strategies for quantifying the relationships between Asian aerosols and their climatic impacts, J. Geophys. Res., 8, 8633, doi:10.1029/2003JD003550, 2003.

Jones, A. P.: Indoor air quality and health, Atoms. Environ, 33, 4535-4564, 1999.

Kahn, R. A., Gaitley, B. J., Garay, M. J., Diner, D. J., Eck, T. F., Smirnov, A., and Holben, B. N.: Multiangle Imaging SpectroRadiometer global aerosol product assessment by comparison with the Aerosol Robotic Network, J. Geophys. Res.-Atmos., 115, D23209, doi:10.1029/2010JD014601, 2010.

King, M. D., Byrne, D. M., Herman, B. M., and Reagan, J. A.: Aerosol size distributions obtained by inversion of spectral optical depth measurements, J. Atmos. Sci., 21, 2153-2167, 1978. 
King, M. D., Kaufman, Y., Tanré, D., and Nakajima, T.: Remote sensing of Tropospheric aerosols from Space: Past, Present, and Future, B. Am. Meteorol. Soc., 80, 2229-2259, 1999.

Kinne, S., Lohmann, U., Feichter, J., Schulz, M., Timmreck, C., Ghan, S., Easter, R., Chin, M., Ginoux, P., Takemura, T., Tegen, I., Koch, D., Herzog, M., Penner, J., Pitari, G., Holben, B., Eck, T., Smirnov, A., Dubovik, O., Slutsker, I., Tanré, D., Torres, O., Mishchenko, M., Geogdzhayev, I., Chu, D. A., and Kaufman, Y. J.: Monthly averages of aerosol properties: A global comparison among models, satellite data and AERONET ground data, J. Geophys. Res., 108, 4634, doi:10.1029/2001JD001253, 2003.

Kinne, S., Schulz, M., Textor, C., Guibert, S., Balkanski, Y., Bauer, S. E., Berntsen, T., Berglen, T. F., Boucher, O., Chin, M., Collins, W., Dentener, F., Diehl, T., Easter, R., Feichter, J., Fillmore, D., Ghan, S., Ginoux, P., Gong, S., Grini, A., Hendricks, J., Herzog, M., Horowitz, L., Isaksen, I., Iversen, T., Kirkevåg, A., Kloster, S., Koch, D., Kristjansson, J. E., Krol, M., Lauer, A., Lamarque, J. F., Lesins, G., Liu, X., Lohmann, U., Montanaro, V., Myhre, G., Penner, J., Pitari, G., Reddy, S., Seland, O., Stier, P., Takemura, T., and Tie, X.: An AeroCom initial assessment - optical properties in aerosol component modules of global models, Atmos. Chem. Phys., 6, 1815-1834, doi:10.5194/acp-6-1815-2006, 2006.

Klett, D.: Stable analytical inversion solution for processing lidar returns, Appl. Opics, 20, 211-220, 1981.

Klett, D.: Lidar inversion with variable backscatter/extinction ratios, Appl. Optics, 31, 1638-1643, 1985.

Koch, D., Schulz, M., Kinne, S., McNaughton, C., Spackman, J. R., Balkanski, Y., Bauer, S., Berntsen, T., Bond, T. C., Boucher, O., Chin, M., Clarke, A., De Luca, N., Dentener, F., Diehl, T., Dubovik, O., Easter, R., Fahey, D. W., Feichter, J., Fillmore, D., Freitag, S., Ghan, S., Ginoux, P., Gong, S., Horowitz, L., Iversen, T., Kirkevåg, A., Klimont, Z., Kondo, Y., Krol, M., Liu, X., Miller, R., Montanaro, V., Moteki, N., Myhre, G., Penner, J. E., Perlwitz, J., Pitari, G., Reddy, S., Sahu, L., Sakamoto, H., Schuster, G., Schwarz, J. P., Seland, Ø., Stier, P., Takegawa, N., Takemura, T., Textor, C., van Aardenne, J. A., and Zhao, Y.: Evaluation of black carbon estimations in global aerosol models, Atmos. Chem. Phys., 9, 9001-9026, doi:10.5194/acp-9-9001-2009, 2009.

Kokhanovsky, A., Bréon, F. M., Cacciari, A., Carboni, E., Diner, D., Di Nicolantonio, W., Grainger, R., Grey, W., Höller, R., Lee, K.H., Li, Z., North, P., Sayer, A., Thomas, G., and von HoyningenHuene, W.: Aerosol remote sensing over land: A comparison of satellite retrievals using different algorithms and instruments, Atmos. Res., 85, 372-394, 2007.

Kotelnikov, V. A.: On the carrying capacity of the ether and wire in telecommunications, in: Material for the First All-Union Conference on Questions of Communication, Izd. Red. Upr. Svyazi RKKA, Moscow, 1933.

Kovalev, V. A.: Sensitivity of the lidar solution to errors of the aerosol backscatter-to-extinction ratio: Influence of a monotonic change in the aerosol extinction coefficient, Appl. Optics, 34, 3457-3462, 1995.

Kovalev, V. A. and Oller, H. M.: Distortion of particulate extinction profiles measured with lidar in a two-component atmosphere, Appl. Optics, 33, 6499—6570, 1994.
Li, Z., Goloub, P., Dubovik, O., Blarel, L., Zhang, W., Podvin, T., Sinyuk, A., Sorokin, M., Chen, H., Holben, B. N., Tanré, D., Canini, M., and Buis, J.-P.: Improvements for ground-based remote sensing of atmospheric aerosol properties by additional polarimetric measurements, J. Quant. Spectrosc. Ra., 110, 19541961, 2009.

Liu, Z., Sugimoto, N., and Murayama, T.: Extinction-to- backscatter ratio of Asian dust observed with high-spectral-resolution lidar and Raman lidar, Appl. Optics, 41, 2760-2767, 2002.

Marenco, F., Santacesaria, V., Bais, A. F., Balis, D., di Sarra, A., Papayannis, A., and Zerefos, C.: Optical properties of tropospheric aerosols determined by lidar and spectrophotometric measurements (Photochemical Activity and Solar Ultraviolet Radiation Campaign), Appl. Optics, 36, 6875-6886, 1997.

Matsumoto, M. and Takeuchi, N.: Effects of misestimated far-end boundary values on two common lidar inversion solutions, Appl. Optics, 33, 6451-6456, 1994.

McCormick, M. P., Wang, P.-H., and Poole, L. R.: Stratospheric aerosols and clouds, in Aerosol-Cloud-Climate Interactions, Academic Press, San Diego, California, 205-222, 1993.

McKendry, I., Strawbridge, K. B., O’Neill, N. T., Macdonald, A. M., Liu, P. S. K., Leaitch, W. R., Anlauf, K. G., Jaegle, L., Fairlie, T. D., and Westphal, D. L.: Trans-Pacific transport of Saharan dust to western North America: A case study, J. Geophys. Res., 112, D01103, doi:10.1029/2006JD007129, 2007.

Mishchenko, M. I., Hovenier, J. W., and Travis, L. D.: Light scattering by nonspherical particles, Elsevier, New York, 2000.

Mishchenko, M. I., Cairns, B., Ha, Travis, L. D., Burg, R., Kaufman, Y. J., Martins, J. V., and Shettle, E. P.: Monitoring of aerosol forcing of climate from space: Analysis of measurement requirements, J. Quant. Spectrosc. Ra., 79/80, 149-161, 2004.

Mishchenko, M. I., Cairns, B., Kopp, G., Schueler, C. F., Fafaul, B. A., Hansen, J. E., Hooker, R. J., Itchkawich, T., Maring, H. B., and Travis, L. D.: Accurate monitoring of terrestrial aerosol and total solar irradiance: introducing the Glory, Mission, B. Am. Meteorol. Soc., 88, 677-691, 2007.

Müller, D., Wandinger, U., and Ansmann, A.: Microphysical particle parameters from extinction and backscatter lidar data by inversion with regularization: Theory, Appl. Optics, 38, 1999.

Müller, D., Mattis, I., Wandinger, U., Ansmann, A., Althausen, D., Dubovik, O., Eckhardt, S., and Stohl, A.: Saharan dust over a Central European EARLINET-AERONET site: Combined observations with Raman lidar and Sun photometer, J. Geophys. Res., 108, 4345, doi:10.1029/2002JD002918, 2003.

Müller, D., Mattis, I., Ansmann, A., Wehner, B., Althausen, D., Wandinger, U., and Dubovik, O.: Closure study on optical and microphysical properties of a mixed urban and Arctic haze air mass observed with Raman lidar and Sun photometer, J. Geophys. Res., 109, D13206, doi:10.1029/2003JD004200, 2004.

Müller, D., Mattis, I., Wandinger, U., Ansmann, A., Althausen, D., and Stohl, A.: Raman lidar observations of aged Siberian and Canadian forest fire smoke in the free troposphere over Germany in 2003: Microphysical particle characterization, J. Geophys. Res., 110, D17201, doi:10.1029/2004JD005756, 2005.

Müller, D., Ansmann, A., Mattis, I., Tesche, M., Wandinger, U., Althausen, D., and Pisani, G.: Aerosol-type-dependent lidar ratios observed with Raman lidar, J. Geophys. Res., 112, D16202, doi:10.1029/2006JD008292, 2007. 
Müller, D., Weinzierl, B., Petzold, A., Kandler, K., Ansmann, A., Müller, T., Tesche, M., Freudenthaler, V., Esselborn, M., Heese, B., Althausen, D., Schladitz, A., Otto, S., and Knippertz, P.: Mineral dust observed with AERONET Sun photometer, Raman lidar, and in situ instruments during SAMUM 2006: Shapeindependent particle properties, J. Geophys. Res., 115, D07202, doi:10.1029/2009JD012520, 2010.

Müller, D., Lee, K.-H., Gasteiger, J., Tesche, M., Weinzierl, B., Kandler, K., Müller, T., Toledano, C., Otto, S., Althausen, D., and Ansmann, A.: Comparison of optical and microphysical properties of pure Saharan mineral dust observed with AERONET Sun photometer, Raman lidar, and in situ instruments during SAMUM 2006, J. Geophys. Res., 117, D07211, doi:10.1029/2011JD016825, 2012.

Müller, D., Veselovskii, I., Kolgotin, A., Tesche, M., Ansmann, A., and Dubovik, O.: Vertical profiles of pure dust and mixed smoke-dust plumes inferred from inversion of multiwavelength Raman/polarization lidar data and comparison to AERONET retrievals and in situ observations, Appl. Optics, 52, 3178-3202, doi:10.1364/AO.52.003178, 2013.

Murayama, T., Sugimoto, N., Matsui, I., Liu, Z., Sakai, T., Shibata, T., Iwsasaka, Y., Won, J.-G., Yoon, S.-C., Li, T., Zhou, J., and Hu, H.: Lidar Network Observation of Asian Dust, in: Advances in Laser Remote sensing, Selected papers 20th Int. Laser Radar Conference (ILRC), Vichy, France, 10-14 July 2000, edited by: Dabas, A., Loth, C., and Pelon, J., Vichy, France, 169-177, 2001.

Nakajima, T., Tanaka, M., and Yamauchi, T.: Retrieval of the optical properties of aerosols from aureole and extinction data, Appl. Optics, 22, 2951-2959, 1983.

Nakajima, T., Tonna, G., Rao, R., Kaufman, Y. J., and Holben, B. N.: Use of sky brightness measurements from ground for remote sensing of particulate polydispersions, Appl. Optics, 35, 2672-2686, 1996.

Nakajima, T., Yoon, S. C., Ramanathan, V., Shi, G.-Y., Takemura, T., Higurashi, A., Takamura, T., Aoki, K., Sohn, B.-J., Kim, S.-W., Tsuruta, H., Sugimoto, N., Shimizu, A., Tanimoto, H., Sawa, Y., Lin, N.-H., Lee, C.-T., Goto, D., and Schutgens, N.: Overview of the Atmospheric Brown Cloud East Asian Regional Experiment 2005 and a study of the aerosol direct radiative forcing in east Asia, J. Geophys. Res., 112, D24S91, doi:10.1029/2007JD009009, 2007.

Nyquist, H.: Certain topics in telegraph transmission theory, Trans. AIEE, 47, 617-644, 1928.

Omar, A. H., Won, J. G., Winker, D. M., Yoon, S. C., Dubovik, O., and McCormick, M. P.: Development of global aerosol models using cluster analysis of AERONET measurements, J. Geophys. Res., 110, D10S14, doi:10.1029/2004JD004874, 2005.

Oshchepkov, S., Sasano, Y., and Yokota, T.: New method for simultaneous gas and aerosol retrievals from space limb-scanning spectral observation of the atmosphere, Appl. Optics, 41, 42344244, 2002.

Papayannis, A., Balis, D., Amiridis, V., Chourdakis, G., Tsaknakis, G., Zerefos, C., Castanho, A. D. A., Nickovic, S., Kazadzis, S., and Grabowski, J.: Measurements of Saharan dust aerosols over the Eastern Mediterranean using elastic backscatter-Raman lidar, spectrophotometric and satellite observations in the frame of the EARLINET project, Atmos. Chem. Phys., 5, 2065-2079, doi:10.5194/acp-5-2065-2005, 2005.
Pickering, K. E., Thompson, A. M., Kim, H., DeCaria, A. J., Pfister, L., Kucsera, T. L., Witte, J. C., Avery, M. A., Blake, D. R., Crawford, J. H., Heikes, B. G., Sachse, G. W., Sandholm, S. T., and Talbot, R. W.: Trace gas transport and scavenging in PEMTropics B South Pacific Convergence Zone convection, J. Geophys. Res., 106, 32591-32602, 2001.

Pilinis, C., Pandis, S. N., and Seinfeld, J. H.: Sensitivity of direct climate forcing by atmospheric aerosols to aerosol size and composition, J. Geophys. Res., 100, 18739-18754, 1995.

Raes, F., Bates, T., McGovern, F., and Liedekerke, M. V.: The 2nd Aerosol Characterization Experiment (ACE-2): general overview and main results, Tellus B, 52, 111-125, 2000.

Ramanathan, V., Crutzen, P. J., Lelieveld, J., Mitra, A. P., Althausen, D., Anderson, J., Andreae, M. O., Cantrell, W., Cass, G. R., Chung, C. E., Clarke, A. D., Coakley, J. A., Collins, W. D., Conant, W. C., Dulac, F., Heintzenberg, J., Heymsfield, A. J., Holben, B., Howell, S., Hudson, J., Jayaraman, A., Kiehl, J. T., Krishnamurti, T. N., Lubin, D., McFarquhar, G., Novakov, T., Ogren, J. A., Podgorny, I. A., Prather, K., Priestley, K., Prospero, J. M., Quinn, P. K., Rajeev, K., Rasch, P., Rupert, S., Sadourny, R., Satheesh, S. K., Shaw, G. E., Sheridan, P., and Valero, F. P. J.: Indian Ocean Experiment: An integrated analysis of the climate forcing and effects of the great Indo-Asian haze, J. Geophys. Res., 106, 28371-28398, doi:10.1029/2001JD900133, 2001.

Remer, L. A., Tanré, D., Kaufman, Y. J., Ichoku, C., Mattoo, S., Levy, R., Chu, D. A., Holben, B., Dubovik, O., Smirnov, A., Martins, J. V., Li, R. R., and Ahmad, Z.: Validation of MODIS aerosol retrieval over ocean, Geophys. Res. Lett., 29, 1618, doi:10.1029/2001GL013204, 2002.

Remer, L. A., Kaufman, Y. J., Tanré, D., Mattoo, S., Chu, D. A., Martins, J. V., Li, R. R., Ichoku, C., Levy, R. C., Kleidman, R. G., Eck, T. F., Vermote, E., and Holben, B. N.: The MODIS aerosol algorithm, products, and validation, J. Atmos. Sci., 62, 947-973, doi:10.1175/JAS3385.1, 2005.

Rodgers, C. D.: Retrieval of atmospheric temperature from remote measurements of thermal radiation, Rev. Geophys., 14, 609-624, 1976.

Russell, P. B., Hobbs, P. V., and Stowe, L. L.: Aerosol properties and radiative effects in the United States East Coast haze plume. An overview of the Tropospheric Aerosol Radiative Forcing Observational Experiment (TARFOX), J. Geophys. Res., 104, 22132222, 1999.

Sasano, Y., Browell, E. V., and Ismail, S.: Error caused by using a constant extinction backscattering ratio in the lidar solution, Appl. Optics, 24, 3929-3932, 1985.

Schoeberl, M. R. and Newman, P. A.: A multiple-level trajectory analysis of vortex filaments, J. Geophys. Res., 100, 2580125816, 1995.

Schuster, G. L., Vaughan, M., MacDonnell, D., Su, W., Winker, D., Dubovik, O., Lapyonok, T., and Trepte, C.: Comparison of CALIPSO aerosol optical depth retrievals to AERONET measurements, and a climatology for the lidar ratio of dust, Atmos. Chem. Phys., 12, 7431-7452, doi:10.5194/acp-12-7431-2012, 2012

Shipley, S. T., Tracy, D. H., Eloranta, E. W., Trauger, J. T., Sroga, J. T., Roesler, F. L., and Weinman, J. A.: High spectral resolution lidar to measure optical scattering properties of atmospheric aerosols, Appl. Optics, 23, 3716-3724, 1983. 
Sinyuk, A., Dubovik, O., Holben, B., Eck, T. F., Bréon, F.M., Martonchik, J., Kahn, R., Diner, D. J., Vermote, E. F., Roger, J.-C., Lapyonok, T., and Slutsker, I.: Simultaneous retrieval of aerosol and surface properties from a combination of AERONET and satellite data, Remote Sens. Environ., 107, 90108, doi:10.1016/j.rse.2006.07.022, 2007.

Sinyuk, A., Dubovik, O., Holben, B., Schafer, J., Giles, D., Eck, T., Slutsker, I., Sorokine, M., Smirnov, A., Bréon, F., and Khan, R.: Multi-sensor aerosol retrievals using joint inversion of AERONET and satellite observations: concept and applications, Eos Trans. AGU, Fall Meet. Suppl., 53, B287, 2008.

Takamura, T., Sasano, Y., and Hayasaka, T.: Tropospheric aerosol optical properties derived from lidar, sun photometer, and optical particle counter measurements, Appl. Optics, 33, 7132-7140, 1994.

Tesche, M., Ansmann, A., Müller, D., Althausen, D., Mattis, I., Heese, B., Freudenthaler, V., Wiegner, M., Esselborn, M., Pisani, G., and Knippertz, P.: Vertical profiling of Saharan dust with Raman lidars and airborne HSRL in southern Morocco during SAMUM, Tellus B, 61, 144-164, 2009.

Tesche, M., Groß, S., Ansmann, A., Müller, D., Althausen, D., Freudenthaler, V., and Esselborn, M.: Profiling of Saharan dust and biomass-burning smoke with multiwavelength polarization Raman lidar at Cape Verde, Tellus B, 63, 649-676, 2011.

Textor, C., Schulz, M., Guibert, S., Kinne, S., Balkanski, Y., Bauer, S., Berntsen, T., Berglen, T., Boucher, O., Chin, M., Dentener, F., Diehl, T., Easter, R., Feichter, H., Fillmore, D., Ghan, S., Ginoux, P., Gong, S., Grini, A., Hendricks, J., Horowitz, L., Huang, P., Isaksen, I., Iversen, I., Kloster, S., Koch, D., Kirkevåg, A., Kristjansson, J. E., Krol, M., Lauer, A., Lamarque, J. F., Liu, X., Montanaro, V., Myhre, G., Penner, J., Pitari, G., Reddy, S., Seland, $\varnothing$., Stier, P., Takemura, T., and Tie, X.: Analysis and quantification of the diversities of aerosol life cycles within AeroCom, Atmos. Chem. Phys., 6, 1777-1813, doi:10.5194/acp-6-1777-2006, 2006.

Toledano, C., Wiegner, M., Groß, S., Freudenthaler, V., Gasteiger, J., Müller, D., Müller, T., Schladitz, A., Weinzierl, B., Torres, B., and O'neill, N. T.: Optical properties of aerosol mixtures derived from sun-sky radiometry during SAMUM-2, Tellus B, 63, 635648, doi:10.1111/j.1600-0889.2011.00573.x, 2011.

Turner, D. D., Ferrare, R. A., Heilman-Brasseur, L. A., Feltz, W. F., and Tooman, T. P.: Automated retrievals of water vapor and aerosol profiles from an operational Raman lidar, J. Atmos. Ocean. Tech., 19, 37-50, 2002.
Twomey, S.: On the numerical solution of Fredholm integral equations of the first kind by the inversion of the linear system produced by quadrature, J. Assoc. Comp. Mach., 10, 97-101, 1963.

Veselovskii, I., Kolgotin, A., Griaznov, V., Müller, D., Franke, K., and Whiteman, D. N.: Inversion of multiwavelength Raman lidar data for retrieval of bimodal aerosol size distribution, Appl. Optics, 43, 1180-1195, 2004.

Veselovskii, I., Dubovik, O., Kolgotin, A., Lapyonok, T., Di Girolamo, P., Summa, D., Whiteman, D. N., Mishchenko, M., and Tanré, D.: Application of randomly oriented spheroids for retrieval of dust particle parameters from multi-wavelength lidar measurements, J. Geophys. Res., 115, D21203, doi:10.1029/2010JD014139, 2010.

Volten, H., Munoz, O., Rol, E., de Haan, J. F., Vassen, W., Hovenier, J. W., Muinonen, K., and Nousiainen, T.: Scattering matrices of mineral aerosol particles at $441.6 \mathrm{~nm}$ and $632.8 \mathrm{~nm}$, J. Geophys. Res., 106, 17375-17401, 2001.

Wagner, J., Ansmann, A., Wandinger, U., Seifert, P., Schwarz, A., Tesche, M., Chaikovsky, A., and Dubovik, O.: Evaluation of the Lidar/Radiometer Inversion Code (LIRIC) to determine microphysical properties of volcanic and desert dust, Atmos. Meas. Tech. Discuss., 6, 911-948, doi:10.5194/amtd-6911-2013, 2013.

Waquet, F., Léon, J.-F., Goloub, P., Pelon, J., Tanré, D., and Deuzé, J.-L.: Maritime and dust aerosol retrieval from polarized and multispectral active and passive sensors, J. Geophys. Res., 110, D10S10, doi:10.1029/2004JD004839, 2005.

Welton, E. J., Campbell, J. R., Berkoff, T. A., Spinhirne, J. D., Tsay, S.-C., Holben, B., and Shiobara, M.: The Micro-pulse Lidar Network (MPL-Net), in: Lidar Remote Sensing in Atmospheric and Earth Sciences, Reviewed and revised papers at the twenty-first International Laser Radar Conference (ILRC21), 812 July, edited by: Bisonnette, L. R., Roy, G., and Vallee, G., Defence R\&D Canada - Vacartier, Quebec, Canada, 285-288, 2002.

Winker, D. M., Hunt, W. H., and McGill, M. J.: Initial perfomance assessment of CALIOP, Geophys. Res. Lett., 34, L19803, doi:10.1029/2007GL030135, 2007.

Yoon, J., von Hoyningen-Huene, W., Vountas, M., and Burrows, J. P.: Analysis of linear long-term trend of aerosol optical thickness derived from SeaWiFS using BAER over Europe and South China, Atmos. Chem. Phys., 11, 12149-12167, doi:10.5194/acp11-12149-2011, 2011. 